\title{
Co-Expression and Functional Interactions of Death Receptor 3 and E-Selectin in Clear Cell Renal Cell Carcinoma
}

\author{
Rafia S. Al-Lamki, ${ }^{*}$ Jun Wang, ${ }^{*}$ Jordan S. Pober, ${ }^{\dagger}$ and John R. Bradley*
}

From the Department of Medicine, * National Institute of Health Research Cambridge Biomedical Research Centre, University of Cambridge, Cambridge, United Kingdom; and the Department of Immunobiology, ${ }^{\dagger}$ Yale University, New Haven, Connecticut

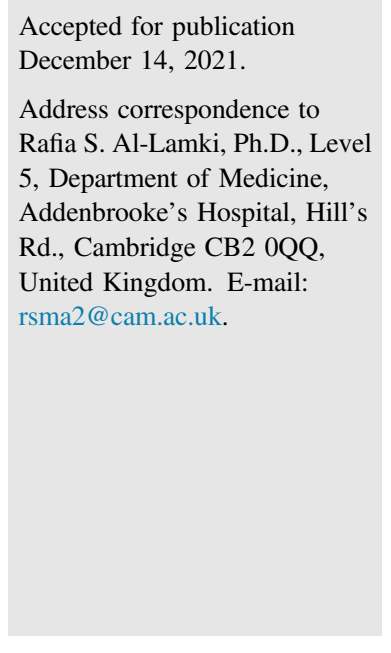

Accepted for publication

December 14, 2021

Address correspondence to Rafia S. Al-Lamki, Ph.D., Level 5, Department of Medicine Addenbrooke's Hospital, Hill's Rd., Cambridge CB2 0QQ, United Kingdom. E-mail rsma2@cam.ac.uk.

\begin{abstract}
Similar to the behavior of inflamed tubular epithelial cells, clear cell renal cell carcinoma (ccRCC) cells express death receptor 3 (DR3 or TNFSFR25) in situ, and expression increases with tumor grade. Surprisingly, E-selectin, which can be induced in endothelial cells by DR3 signaling, is also expressed by $\operatorname{ccRCC}$ cells and increases with tumor grade. In ccRCC organ cultures, addition of tumor necrosis factor-like $1 \mathrm{~A}$ (TL1A or TNFSF15), the ligand for DR3, activates NF- $\mathrm{KB}$ and mitogen-activated protein kinases, induces both DR3 and E-selectin expression in an NF- $\mathrm{KB}$-dependent manner, and promotes cell cycle entry. DR3 immunoprecipitated from ccRCC tissue contains sialyl Lewis $\mathrm{X}$ moieties (the ligand recognized by E-selectin), proximity ligation assays reveal DR3, and E-selectin interacts on ccRCC cells. Similar to that with the addition of TL1A, the addition of soluble E-selectin to cCRCC organ cultures activates NF- $\mathrm{KB}$ and mitogen-activated protein kinases in $\mathrm{ccRCC}$ cells and increases both DR3 and Eselectin expression and cell-cycle entry. In contrast, normal renal tubular epithelium, which poorly expresses DR3, is minimally responsive to either of these ligands. These data suggest a functional role for autocrine/paracrine DR3/E-selectin interactions in CCRCC and its progression, revealing a potential new target for therapeutic intervention. (Am J Pathol 2022, 192: 722-736; https://doi.org/10.1016/ j.ajpath.2021.12.010)
\end{abstract}

Renal cell carcinoma (RCC) is the most common type of kidney cancer, with the clear cell subtype (ccRCC) representing approximately $70 \%$ of cases. ${ }^{1}$ Prognosis for highgrade RCC is poor, and new approaches to treat this tumor are needed. This study reports a new autocrine/ paracrine signaling pathway in ccRCC cells involving death receptor 3 (DR3) and E-selectin that could be a target for new therapies.

DR3, also designated as TNFRSF25, TRAMP, LARD, WSL-1, Apo-3, or TR3, is one of eight death domain (DD)containing receptors of the tumor necrosis factor (TNF) superfamily. ${ }^{2}$ On binding of its ligand, known as tumor necrosis factor-like 1A (TL1A also designated as TNFSF15) to DR3, signaling proteins, such the TNF receptor type 1-associated DD protein, TNF receptor associated factor 2 protein, and receptor-interacting serine/ threonine-protein kinase 1 , are recruited to the cytosolic DD of the activated receptor, initiating new expression of proteins involved in immune responses and cell survival. ${ }^{3-5}$ After some delay, the Fas associated via DD protein may also be recruited to this complex, initiating the extrinsic pathway of apoptosis. DR3 is up-regulated on renal tubular epithelial cells (TECs) and vascular endothelial cells (ECs) in settings of renal injury and binding of TL1A to DR3,

\footnotetext{
Supported by the National Institute for Health Research (NIHR) Cambridge Biomedical Research Centre (IS-BRC-1215-20014).

Disclosures: None declared.

The views expressed are those of the authors and not necessarily those of the NIHR or the Department of Health and Social Care.
} 
which activates the same signaling pathways as TNF- $\alpha$ binding to TNF receptor type 1 , can trigger cell injury. ${ }^{6,7}$ However, others have reported effects of DR3 signaling that reduce acute kidney injury by antagonizing the proapoptotic signals induced by TNF. ${ }^{8,9}$ TL1A mRNA is abundantly expressed in kidney tissue ${ }^{7}$ and colon cancer. ${ }^{10}$ Recent studies have reported DR3 expression by some tumors, but its role in tumorigenesis is controversial; it has been implicated as both an anticancer ${ }^{11}$ and procancer molecule. $^{12,13}$

E-selectin (CD62E, also known as endothelial leukocyte adhesion molecule 1), is a type Ia transmembrane protein that contains lectin-like and epithelial growth factor-like domains, followed by short cysteine-rich repeats. ${ }^{14}$ It is primarily expressed by activated, but not resting, postcapillary venular ECs, ${ }^{15}$ but rare epithelial cell expression of E- selectin has been previously reported. ${ }^{16,17}$ E-selectin is transcriptionally induced by cytokines such as TNF or IL-1, mediated by NF- $\mathrm{KB}$ and a variant of activator protein $1 .{ }^{18-20}$ These are the same signaling pathways activated by TL1A binding to DR3. In humans, E-selectin plays a critical and nonredundant role in tethering and rolling of leukocytes to ECs, allowing their subsequent extravasation into inflamed tissues. ${ }^{21}$ Expression of E-selectin has been reported on some tumor vasculatures, ${ }^{22-24}$ where it has been proposed as a target for metastasis of tumor cells bearing E-selectin ligands, ${ }^{13,25-29}$ typically cell surface proteins or lipids bearing sialyl Lewis $\mathrm{X}\left(\mathrm{sLe}^{\mathrm{X}}\right)$ or sialyl Lewis A. ${ }^{13,30-32} \mathrm{sLe}^{\mathrm{X}}$ may be detected using a monoclonal antibody that binds to human skin-homing $\mathrm{T}$ cells where the antigenic determinant is designated as cutaneous lymphocyte antigen (CLA). $\mathrm{sLe}^{\mathrm{X}}$ expression increases from normal tissue to early-stage bladder or renal cancers to metastatic disease. ${ }^{33,34}$ In RCC, sLe ${ }^{\mathrm{X}}$ correlates with conventional histopathologic parameters and serves as an indicator for prognosis. ${ }^{35}$ Elevated levels of soluble serum E-selectin are associated with tumor grade, tumor stage, and metastases in breast cancer. ${ }^{36}$ In addition to adhesion to ECs, one report has suggested that in colon carcinoma, E-selectin binds to and can serve as a functional ligand for DR3, triggering activation of p38 and ERK mitogen-activated protein kinases (MAPKs) and conferring metastatic and survival advantages. ${ }^{13}$

Because DR3 can be induced on normal kidney TECs by inflammation, we hypothesized that it might also play a role in their malignant counterparts, namely, ccRCC cells. In the current study, both DR3 and, unexpectedly, E-selectin were expressed on ccRCC cells and the expression of both molecules increased with tumor grade. DR3 extracted from ccRCC tumors bore sLe $^{\mathrm{X}}$ moieties and tumor cell E-selectin appeared to be complexed with tumor cell DR3 in situ as assessed by proximity ligation assay. In ccRCC, organ culture exogenous E-selectin, like exogenous TL1A, acted as a DR3 ligand, leading to activation of NF- $\kappa \mathrm{B}$ and MAPKs, increased expression of both DR3 and E-selectin, and increased cell cycle entry of ccRCC cells.

\section{Materials and Methods}

\section{Reagents and Antibodies}

Goat anti-human DR3 (catalog number sc6175), rabbit anti-human DR3 (H-300) (catalog number sc7907), mouse anti-human E-selectin (catalog number sc8419), mouse antihuman phosphorylated NF-кBp65 (catalog number sc8008), mouse pancytokeratin (C11) (catalog number sc8018), rabbit anti-pancytokeratin (catalog number sc15367), and mouse anti-human phosphorylated ERK (E-4; $\mathrm{Tyr}^{204}$ ) (catalog number sc7383) antibodies are from Santa Cruz Biotechnology, Inc. (Heidelberg, Germany). Rabbit antihuman DR3 (catalog number GTX105713), mouse antihuman E-selectin (catalog number GTX52484), and mouse anti-human sLe ${ }^{\mathrm{X}}$ (catalog number GTX39137) antibodies are distributed by Stratech Scientific (Ely, UK). Mouse anti-sLe ${ }^{\mathrm{X}}$ antibody (catalog number AGM-209YJ) is distributed by 2BScientific Ltd. (Upper Heyford, UK). Purified mouse anti-human CLA-1 antibody (catalog number 610882) is from BD Biosciences (Berkshire, UK), and rabbit anti-human SCARBI (anti-CLA-1) (catalog number HPA072449) antibody is distributed by Cambridge Bioscience (Cambridge, UK). Goat anti-human E-selectin antibody (catalog number BBA18) is from Merck Life Science UK Limited (Watford, UK). Rabbit anti-human E-selectin (catalog number ab18981) and rabbit anti-human CD31 (platelet endothelial cell adhesion molecule) (catalog number 166994) antibodies are from Abcam (Cambridge, UK). Rabbit anti-human phosphorylated p38 MAPK (Thr180/ Tyr183) (3D7) (catalog number 9215s), rabbit anti-human phosphorylated NF- $\kappa B p 65^{\text {Ser276 }}$ (catalog number cs-3037), and mouse anti-human CD31 (catalog number cs-3528) antibodies are from Cell Signaling Technology (London, UK). Rabbit anti-human phosphorylated p38 MAPK (Thr180, Tyr183) (catalog number -684G), rabbit antihuman CD15/Fut4/SSEA-1 polyclonal antibody (catalog number BS-1702R), rabbit anti-human CD68 (catalog number PA5-32330), and 3,3'-diaminobenzidine tetrahydrochloride substrate kit (catalog number 34,002) are from Thermo Fisher Scientific (Cambridge, UK). Rabbit anti-phosphorylated JNK (Thr183, Tyr185) antibody (clone 3F7, ZooMAb; catalog number ZRB1173) is from Merck Life Science UK Ltd. Monoclonal mouse anti-human cytokeratin (clone AE1/AE3 catalog number 3515) and mouse anti-human CD45 (leukocyte common antigen, clone 2B11 + PD7/26; catalog number GA751) are from Agilent Technologies LDA UK Ltd. (Cheshire, UK). Mouse antihuman DR3/TNFRSF25 antibody (catalog number MAB943), goat anti-human TL1A/TNFSF15 antibodies (catalog number AF744), human recombinant (rh) TL1A protein, anti-goat $\mathrm{NL}^{493}$ (catalog number NL003), anti-goat NL-557 (catalog number NL001), anti-rabbit NL ${ }^{493}$ (catalog number NL006), anti-rabbit $\mathrm{NL}^{557}$ (catalog number NL004), anti-mouse $\mathrm{NL}^{493}$ (catalog number NL007), antimouse $\mathrm{NL}^{493}$ (catalog number NL009), and sheep anti- 
human CD14 (catalog number AB383) antibodies are all from R\&D Systems (Abingdon, UK). Soluble E-selectin (carrier-free) (catalog number 21-7178) was purchased from Tonbo Biosciences (San Diego, CA). Human selectin-E antisense and sense digoxigenin-labeled DNA oligonucleotides probes were purchased from Eurofins Genomics UK Limited (Wolverhampton, UK). Horse anti-goat and goat anti-rabbit horseradish peroxidase-conjugated antibodies and Vectashield Mounting Media were purchased from Vector Laboratories Ltd. (Peterborough, UK). Chicken antirabbit Alexafluor ${ }^{488}$, goat anti-mouse Alexafluor ${ }^{568}$, and anti-rabbit Alexafluor ${ }^{405}$ were purchased from Invitrogen Europe Ltd. (Paisley, UK). The ECL system was purchased from Amersham Pharmacia Biotech UK Ltd. (distributed by Merck) and Duolink in situ reagents and probes anti-mouse minus (catalog number DUO92004) and anti-rabbit plus (catalog number DUO92002) were purchased from Merck.

\section{Tissue Samples}

Experiments using human tissue were performed with informed consent of patients and approval of the local ethics committee and Cambridge University Hospitals Tissue Bank. RCC tissue obtained from radical nephrectomy specimens was immediately excised from tumors that grossly appeared to be ccRCC. This tumor classification was later verified by routine histologic assessment of paraffin-wax embedded samples. Non-clear cell histologic tumor types (eg, papillary, chromophobe, and collecting duct $)^{37}$ were excluded, and only ccRCC, graded according to the four-tiered Fuhrman nuclear grading system ${ }^{38}$ and pathologically staged based on the TNM classification, ${ }^{39,40}$ was used. Tissue samples from 40 patients were collected and scored as Fuhrman grade $1(n=10)$, Fuhrman grade 2 $(n=10)$, Fuhrman grade $3(n=10)$, and Fuhrman grade 4 $(n=10)$. In parallel, adjacent non-tumor kidney (NK) $(n=40)$, categorized histologically as normal kidney cortex, was collected in sites remote from the tumor. All samples were fixed overnight at $4^{\circ} \mathrm{C}$ in $4 \%$ formaldehyde in $0.1 \mathrm{~mol} / \mathrm{L}$ phosphate buffer ( $\mathrm{pH}$ 7.6) and paraffin wax embedded for immunofluorescence or snap frozen in isopentane cooled in liquid nitrogen. Parallel unfixed fresh samples were processed for organ culture experiments. Sections $5 \mu \mathrm{mol} / \mathrm{L}$ thick were prepared for subsequent experiments, and hematoxylin and eosin (H\&E) staining was performed for morphologic studies.

\section{Kidney Organ Cultures}

As previously described, ${ }^{39}$ duplicate $<1-\mathrm{mm}^{3}$ fragments of ccRCC (grade 1/2) and adjacent NK ( $n=5$ per study group) were obtained immediately from surgically excised specimens. Fragments of tissue were placed in a Corning flat-bottomed, 96-well tissue culture plate (Appleton Woods Limited, Birmingham, UK) and immediately immersed in Medium 199 containing 10\% heat inactivated fetal calf serum (TCS, Bucks, UK) and $2.2 \mathrm{mmol} / \mathrm{L}$ glutamine.
Multiple randomized samples from each patient were used to obtain parallel-group comparisons and to assess the reliability and reproducibility of these assays. Tissue was left in media alone [untreated (UT) controls] or pretreated with rhTL1A $(0.2 \mu \mathrm{g} / \mathrm{mL})$ (R\&D Systems, Oxford, UK) ${ }^{39,41}$ and soluble E-selectin (sE-selectin) $(5 \mu \mathrm{g} / \mathrm{mL}$ ) (Tonbo Biosciences) for 3 hours at $37^{\circ} \mathrm{C}$. In parallel, some organ cultures were pretreated with $5 \mu \mathrm{mol} / \mathrm{L}$ of the NF- $\mathrm{BB}$ inhibitor ${ }^{42}$ BAY11-7082 for 1 hour at $37^{\circ} \mathrm{C}$ before treatment with TL1A or sE-selectin for 3 hours at $37^{\circ} \mathrm{C}$. All cultures were harvested, half of the samples were fixed in $4 \%$ formaldehyde for 1.5 hours at $4^{\circ} \mathrm{C}$ and processed for paraffin wax embedding, and half were snap frozen and stored at $-70^{\circ} \mathrm{C}$ for cryosectioning. $\mathrm{H} \& \mathrm{E}$ was performed formalin-fixed, paraffin-embedded (FFPE) sections for morphologic studies.

\section{IF and IHC}

The $5 \mu \mathrm{mol} / \mathrm{L}$ FFPE sections or cryosections of ccRCC, $\mathrm{NK}$, and corresponding organ cultures were subjected to immunofluorescence (IF) and immunohistochemistry (IHC) as previously described. ${ }^{41}$ Briefly, some sections were incubated with antibodies to DR3 and/or E-selectin or in combination with anti-CD31, anti-cytokeratin, anti-CLA-1, anti-sLe ${ }^{\mathrm{X}}$, antiphosphorylated p38(Thr180/ Tyr182), anti-ERK(Tyr20) or anti-JNK (Thr183/Tyr185). To determine the presence of leukocytes, parallel sections of ccRCC and NK were incubated with anti-CD45 alone or with CD15, CD14, or CD68. The intensity of fluorescence was calculated as the corrected total cell fluorescence (CTCF) using ImageJ software version 1.53a (NIH, Bethesda, MD; http://imagej.nih.gov/ij) to control for local background fluorescence. The following formula was used to calculate CTCF: integrated density - (area of selected cell $\times$ mean fluorescence of background readings). Antibody-binding sites were visualized with fluorochrome-conjugated secondary antibodies (Alexa Fluor ${ }^{488}$ or Alexa Fluor ${ }^{568}$ or Alexa Fluro ${ }^{405}$ ) plus Hoechst 333,342 for nuclei detection. The brightest fluorophores were used for low-abundant proteins to maximize sensitivity and with narrow emission spectra to avoid bleed-through. The indirect IF amplification technique was used, which permits simultaneous detection of two antibodies raised in the same species. ${ }^{43}$ After IF, all sections were washed in phosphate-buffered saline, mounted in Vectashield mounting media, and imaged with a Leica SPE confocal laser scanning microscope (Leica Microsystem Ltd., Milton Keynes, UK).

In addition, IHC was used on organ cultures treated with TL1A or sE-selectin with or without Bay 11-7089 to examine expression of NF- $\kappa B p 65$ - $^{\text {Ser276 }}$ and phosphorylated histone- $3_{3}{ }^{\mathrm{Ser} 10}\left(\mathrm{pH} 3-{ }^{\mathrm{Ser} 10}\right)$. Endogenous peroxidase was blocked using $30 \% \mathrm{H}_{2} \mathrm{O}_{2}$ in absolute methanol for 30 minutes at room temperature before incubation with blocking buffer $(10 \%$ fetal calf serum in 
phosphate-buffered saline) for 1 hour in room temperature followed by 1:100 dilution of primary antibodies overnight at $4^{\circ} \mathrm{C}$. After rinses in phosphate-buffered saline, sections were incubated with 1:200 dilution of secondary antibodies for 1 hour in room temperature and antibody binding sites visualized using 3,3'-diaminobenzidine tetrahydrochloride (Thermo Fisher Scientific) plus $0.01 \% \quad \mathrm{H}_{2} \mathrm{O}_{2}$ and viewed using a Nikon Optiphot-2 microscope. To quantify the intensity of immunostaining, we imported images of 3,3'-diaminobenzidine tetrahydrochloride-stained sections into ImageJ, and the mean intensity of staining was determined. Negative controls included replacement of the primary antibody with an isotype-specific serum.

\section{Immunoprecipitation and Immunoblotting}

Total proteins were extracted from clinical samples of ccRCC grades 1 to 4 and adjacent NK with radioimmunoprecipitation assay lysis buffer containing protease and phosphatase inhibitors (Merck Life Sciences UK Ltd), and protein was quantified using a bicinchoninic acid kit (Merck). DR3 epitope was pulled down from tissue extracts using rabbit anti-DR3 antibody and with Magnetic Dynabeads-Protein G (catalog number 10007D; Fischer Scientific UK Ltd., Loughborough, UK) following the manufacturer's instructions. Briefly, Dynabeads-Protein G was suspended in antibody binding and washing buffer containing anti-DR3 antibody and incubated for 10 minutes at room temperature. The mixture was then placed on the magnet and supernatant removed. The Dynabeads-Protein $\mathrm{G}$ antibody complex was resuspended in binding and washing buffer and antigen-containing samples (typically 100 to $1000 \mu \mathrm{L}$ ) were added and incubated on a rotor for 10 minutes at room temperature. The mixture was then placed on the magnet and supernatant removed. The Dynabeads-Protein $G$ antibody antigen complex was rinsed in washing buffer and resuspended in elution buffer for 2 minutes at room temperature. The tube was placed on the magnet and the supernatant/sample transferred to a clean tube. Eluates were than resuspended in the SDS sample buffer and incubated for 10 minutes at $70^{\circ} \mathrm{C}$ and subjected to immunoblotting. Then $50 \mu \mathrm{g}$ of total protein per sample was separated by SDS-PAGE. After transfer to a nitrocellulose membrane, proteins were probed with 1:1000 dilution mouse anti-CLA-1 overnight at $4{ }^{\circ} \mathrm{C}$, and the signal was detected using Super Signal West Pico Chemiluminescent Substrate according to the manufacturer's instructions (Fisher Scientific UK Ltd.).

\section{In Situ PLA}

FFPE sections of ccRCC and adjacent NK organ cultures treated with TL1A or sE-selectin or left UT in media alone (negative controls) were subjected to proximity ligation assay (PLA) as previously described. ${ }^{44}$ In brief, sections were incubated with rabbit anti-DR3 and mouse anti-E-selectin or anti-CLA-1 or anti-sLe ${ }^{\mathrm{X}}$ antibodies overnight at $4^{\circ} \mathrm{C}$. This procedure was followed by a mixture of 1:5 PLA probes (anti-mouse and anti-rabbit antibodies attached with different oligonucleotides, which can ligate through the addition of two other oligonucleotides in ligation solution) for 1 hour. After rinses in $1 \times$ wash buffer A (provided with the kit), sections were incubated in a ligation solution for 30 minutes at $37^{\circ} \mathrm{C}$ and then rinsed in $1 \times$ wash buffer $\mathrm{A}$ and incubated in amplification solution in a dark humidity incubator for 100 minutes at $37^{\circ} \mathrm{C}$. Slide were then washed in $1 \times$ and $0.01 \times$ wash buffer B (provided with the kit) and mounted in Vectamount mounting medium with DAPI. For negative controls, the primary antibody was replaced with isotype-specific serum. Sections were examined on confocal laser scanning microscope, and red fluorescence dots, indicative for protein localization, were counted using ImageJ and quantified with GraphPad Prism version 9.0 software (GraphPad, La Jolla, CA).

\section{In Situ Hybridization}

Nonradioactive in situ hybridization was performed on 5$\mu \mathrm{m}$ FFPE sections of ccRCC and adjacent NK organ cultures as previously described. ${ }^{6,41,45}$ Briefly, sections were incubated overnight at $37^{\circ} \mathrm{C}$ with hybridization solution that contained single-stranded antisense DNA oligonucleotide probes $5^{\prime}$ end labeled with digoxigenin specific for human E-selectin $4 \mu \mathrm{g} / \mathrm{mL}$ (5'-ATTGTCCCCTAGCAAGGCAT$\left.3^{\prime}\right)$ and for human DR3 (5'-AGTCTAGGCA-TGC TTGGCAG-TAGAAGGGTG-AACTGCTGACATTGGCT G-ACCTGGCACT-3') (Eurofins Genomics UK Limited) followed by alkaline phosphatase-conjugated sheep antidigoxigenin antibody (Roche Diagnostics Ltd., West Sussex, UK) for 2 hours at room temperature and visualized with alkaline phosphatase substrate 5-brom-4-chloro-3indoxyly phosphate/nitro blue tetrazolium chloride solution (Merck). Negative controls included incubation of sections with a sense probe to DR3 or E-selectin. The sections were visualized on Leitz Laborlux 12 microscopy equipped with an Infinity 2 camera.

\section{Statistical Analysis}

The mean number of tumor cells and normal TECs positive for NF- $\kappa$ Bp $65 p_{-}-{ }^{\text {Ser276 }}$ and $\mathrm{pH} 3-{ }^{\text {Ser10 }}$ and positive cells for CD45 and CD15, CD14, or CD68 were counted in 10 random high-power fields of view at $\times 40$ magnification and divided by the total number of cells to generate the percentage of positive cells. The assays were repeated in three or more independent experiments, and results are expressed as means \pm SEM. Statistical significance was assessed using an unpaired two-tailed $t$-test and analysis of variance using GraphPad Prism. 


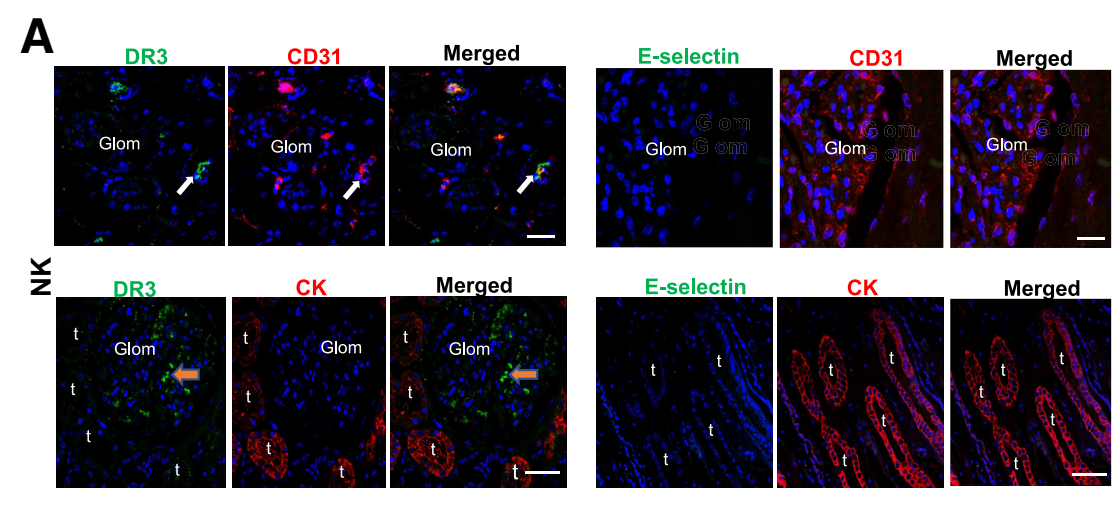

B
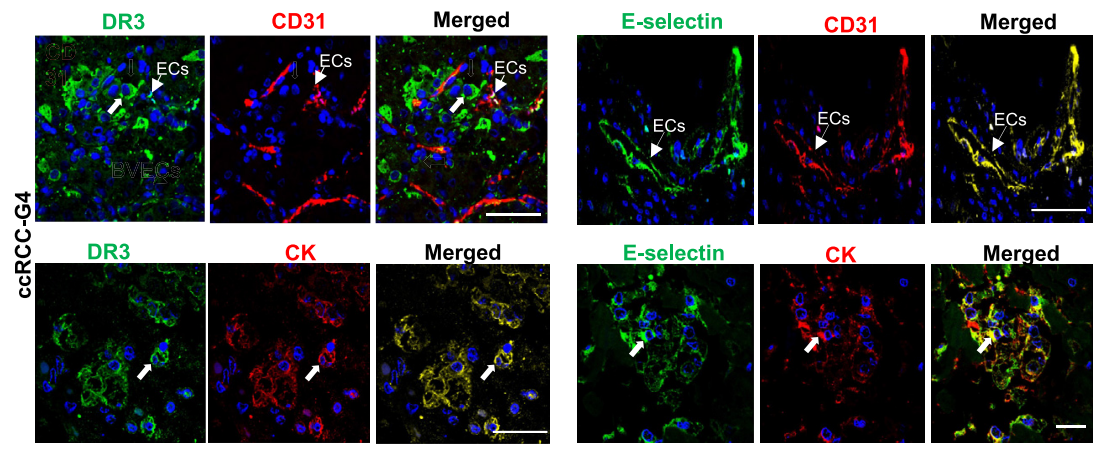

C

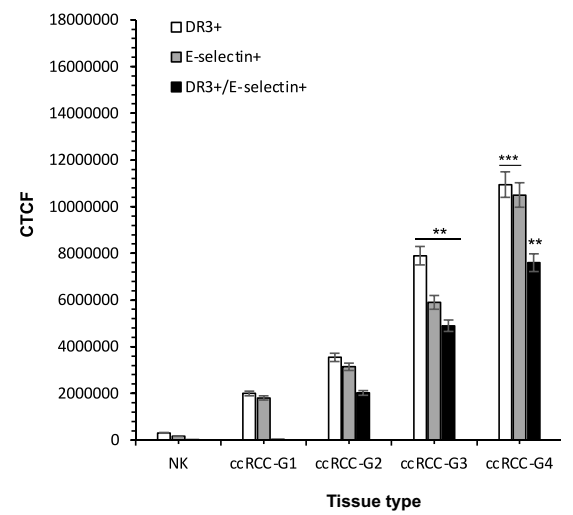

Figure 1 Representative confocal images of dual immunofluorescence staining for death receptor 3 (DR3) or E-selectin and CD31 or cytokeratin (CK) in clear cell renal cell carcinoma (ccRCC) Fuhrman grade 4 (G4) and adjacent normal kidney (NK). A: A rare signal for DR3 is seen in CD31 ${ }^{+}$microvascular endothelial cells (ECS) (arrows) and in resident leukocytes in glomeruli (glom) (orange arrows) in NK. E-selectin is absent in NK. B: In comparison, a remarkably strong signal for both proteins is seen in $\mathrm{CD}_{3} 1^{+}$vascular ECs and in $\mathrm{CK}^{+}$tumor cells (white arrows). C: Quantification of mean fluorescence intensity calculated as corrected total fluorescence (CTCF) [integrated density - (area of selected cell $\times$ mean fluorescence of background readings)] for DR3 and E-selectin expression in ccRCC grades 1 to 4 (G1 to G4) and in NK. Nuclei were counterstained with Hoechst 333342 (blue). Data are expressed as means \pm SEM. $n=10$ per group with similar results. ${ }^{* *} P<0.01,{ }^{* * *} P<0.001$. Scale bars: $25 \mu \mathrm{M}(\mathbf{A}$, upper panel); $50 \mu \mathrm{M}(\mathbf{A}$, lower panel); $100 \mu \mathrm{M}(\mathbf{B}$, upper panel); $50 \mu \mathrm{M}$ (B, lower panel). Original magnification, $\times 40$. $t$, tubular epithelial cells.

\section{Results}

DR3 and E-Selectin Are Highly Expressed in Tumor Cells in $\mathrm{CCRCC}$

DR3 protein expression was examined in clinical samples of ccRCC grades 1 to 4 and adjacent NK. Sections of NK and low-grade ccRCC (grades 1 and 2) demonstrated only a rare signal for DR3 on resident leukocytes in some glomeruli and in ECs of occasional interlobular arteries, with the latter also positive for expression of CD31 (an EC marker) but rarely on TECs and positive for expression of cytokeratin (an epithelial cell marker). These findings are concordant with the earlier report of expression in noninflamed kidney. ${ }^{6}$ A similar pattern of staining for E-selectin was detected on parallel sections. In comparison, staining for both proteins was elevated in higher-grade ccRCC (grades 3 and 4) mainly confined to cytokeratin-positive tumor cells and CD31 ${ }^{+}$ microvascular ECs (Figure 1, A and B, quantified in Figure 1C and Supplemental Figure S1, A-D). Parallel sections stained with $\mathrm{H} \& \mathrm{E}$ showed pleiotropic nuclei in tumor cells in ccRCC (Figure 2, A-F), and IF staining of similar sections using panleukocyte marker CD45 in combination with CD15, CD14, or CD68 showed a high number of infiltrating cells composed of granulocytes, monocytes, and tissue-associated macrophages in the tumor microenvironment (Supplemental Figure 2A, quantified in Supplemental Figure 2B). In addition, co-signal for DR3 and E-selectin was seen in approximately $35 \%$ of tumor cells in ccRCC grade 4 compared with $<5 \%$ in cRCC grade 1 and a negligible level of co-signal detected in adjacent NK (Figure 2, A-E, quantified in Figure 2F). These patterns of expression were similar across multiple different ccRCC samples of the same histologic grade, and a similar staining pattern was seen using different DR3 or E-selectin antibodies. 
CLA-1 and E-Selectin Binding Carbohydrate Moiety sLe ${ }^{\mathrm{X}}$ Are Highly Expressed in Tumor Cells and Are Associated with DR3 in CCRCC

Epitopes recognized by anti-CLA-1 antibodies and other Eselectin-binding carbohydrate moiety $\mathrm{sLe}^{\mathrm{X}}$-bearing molecules are highly expressed in tumor cells and are associated with DR3 in ccRCC. A relationship among CLA-1 molecules, $\mathrm{sLe}^{\mathrm{X}}$ determinants, and E-selectin has been previously reported. ${ }^{46}$ E-selectin binds to proteins that bear sLe ${ }^{\mathrm{X}}$ oligosaccharides. ${ }^{13}$ Therefore, whether CLA-1 was associated with DR3 in ccRCC was examined by immunoprecipitating DR3 from extracts of ccRCC and adjacent NK, separating the immunoprecipitates by SDS-PAGE, and immunoblotting with anti-CLA-1 antibody. Co-immunoprecipitation of CLA-1 with DR3 was observed in all ccRCC extracts and to a much less extent in NK extracts (Figure 3A). FFPE sections from corresponding tissue were next analyzed for the expression of DR 3 and CLA-1 or sLe ${ }^{\mathrm{X}}$ by dual IF and a strong signal for CLA-1 or $\mathrm{sLe}^{\mathrm{X}}$ but not DR3 was found in normal TECs. In comparison, co-signal for DR3 and CLA-1 or sLe ${ }^{\mathrm{X}}$ was accentuated in tumor cells in ccRCC and more pronounced in high-grade tumors (grades 3 and 4) (Figure 3, B and C, Supplemental Figures 3, A and B). These data suggest that DR3 expressed by ccRCC cells contains CLA-1 and $\mathrm{sLe}^{\mathrm{X}}$, and that together these molecules could be ligands for E-selectin.

\section{$\mathrm{DR}^{+}{ }^{+}$ccRCC Cells Are Responsive to TL1A}

TL1A, the principal ligand for DR3, is up-regulated in TECs and vascular ECs in kidney inflammation and injury, and signaling through DR3 can activate NF- $\kappa \mathrm{B}$ signaling in organ culture of human kidney. ${ }^{7}$ Moreover, various MAPKs, including ERKs, JNKs, and p38 MAPK, contribute to tumor cell growth and survival, and phosphorylation of JNK is increased in ccRCC. ${ }^{47}$ Whether DR3 in ccRCC cells was functional was assessed using a human organ culture model
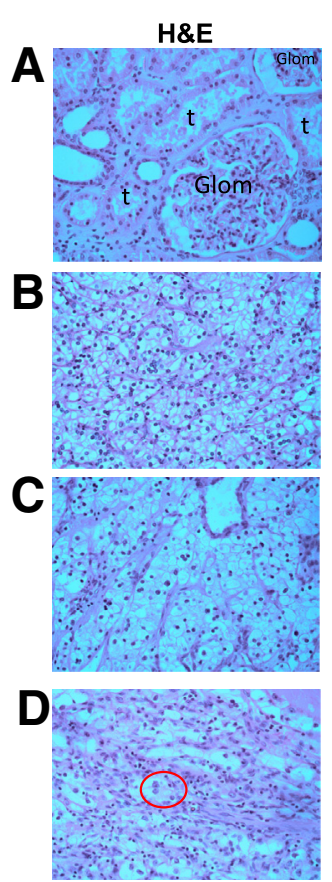

E

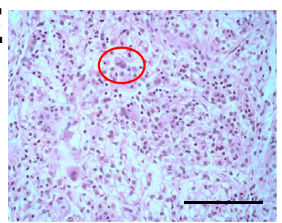

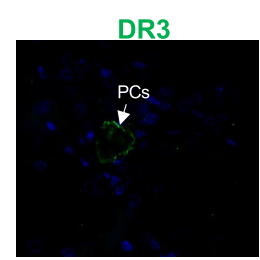
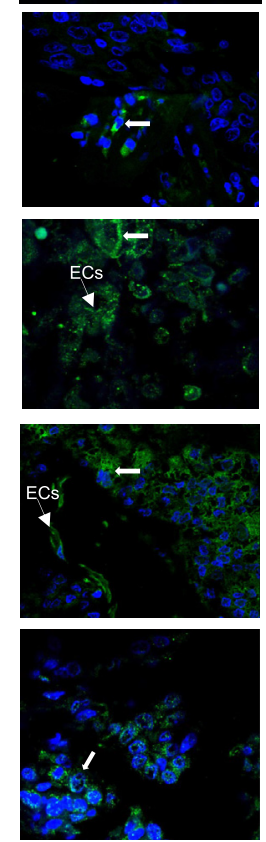
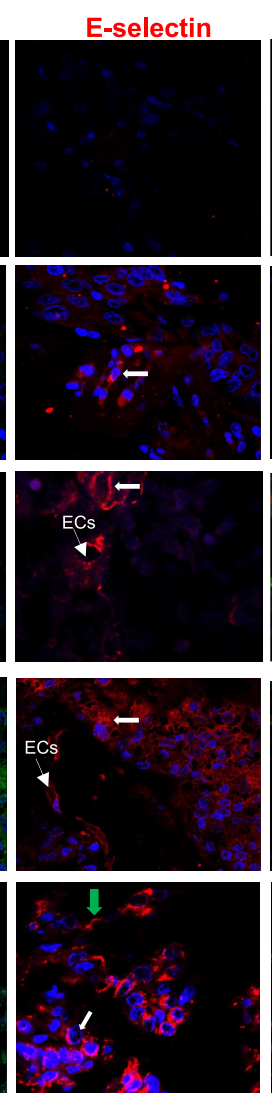
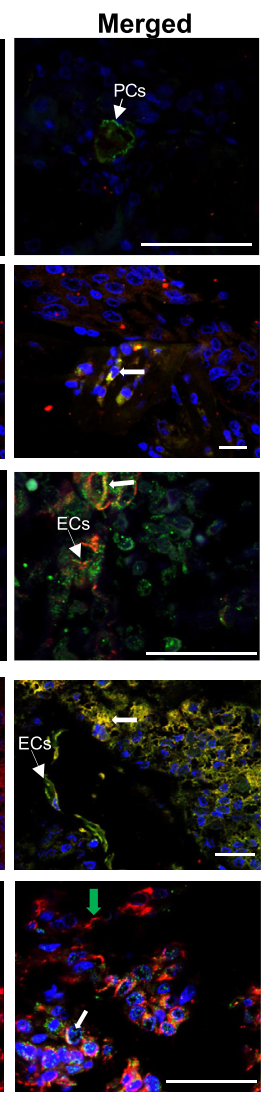

\section{$\mathbf{F}$}

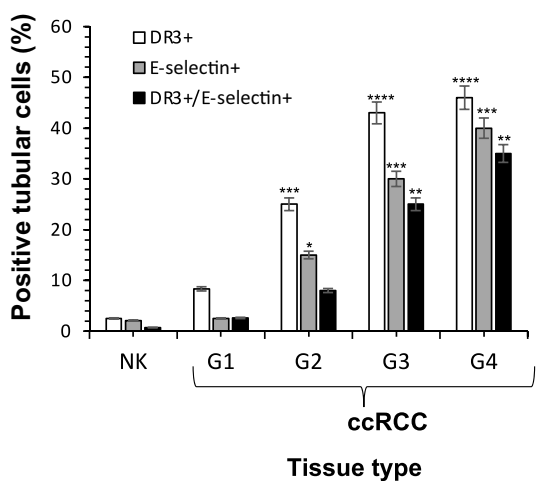

Figure 2 Hematoxylin and eosin (H\&E) and representative confocal images of dual immunofluorescence staining for death receptor 3 (DR3) or E-selectin and CD31 or cytokeratin (CK) in clear cell renal cell carcinoma (CCRCC) Fuhrman grades 1 to 4 and adjacent normal kidney (NK) (A). B: Fuhrman grade 1. C: Fuhrman grade 2. D: Fuhrman grade 3. E: Fuhrman grade 4. (Red circles indicate pleiotropic nuclei in grade 3 and 4 tumors.) A rare signal for DR3 but not Eselectin is seen in interlobular capillaries (PCS) in NK. In comparison, all grades of ccRCC show co-localization of the proteins in tumor cells (white arrows) and in vascular endothelium (ECs), more pronounced in high-grade tumors (grades 3 and 4). A few vascular ECs in high-grade ccRCC were positive for E-selectin but negative for DR3 (green arrows). F: Quantification of the percentage of tumor cells in ccRCC and normal tubular epithelial cells ( $t$ ) in NK. Nuclei were counterstained with Hoechst 333342 (blue). Data are expressed as means \pm SEM. $n=10$ per group with similar results. ${ }^{*} P<0.05,{ }^{* *} P<0.01,{ }^{* * *} P<0.001$, and ${ }^{* * * * P}<0.0001$. Scale bars: $75 \mu \mathrm{mol} / \mathrm{L}$ (A, merged), $25 \mu \mathrm{M}$ (B and $\mathbf{D}$, merged); $50 \mu \mathrm{M}$ (C and $\mathbf{E}$, merged); $100 \mu \mathrm{M}(\mathbf{E}, \mathrm{H} \& \mathrm{E})$. Original magnification, $\times 100$ (light micrographs); $\times 40$ (confocal images). 
A
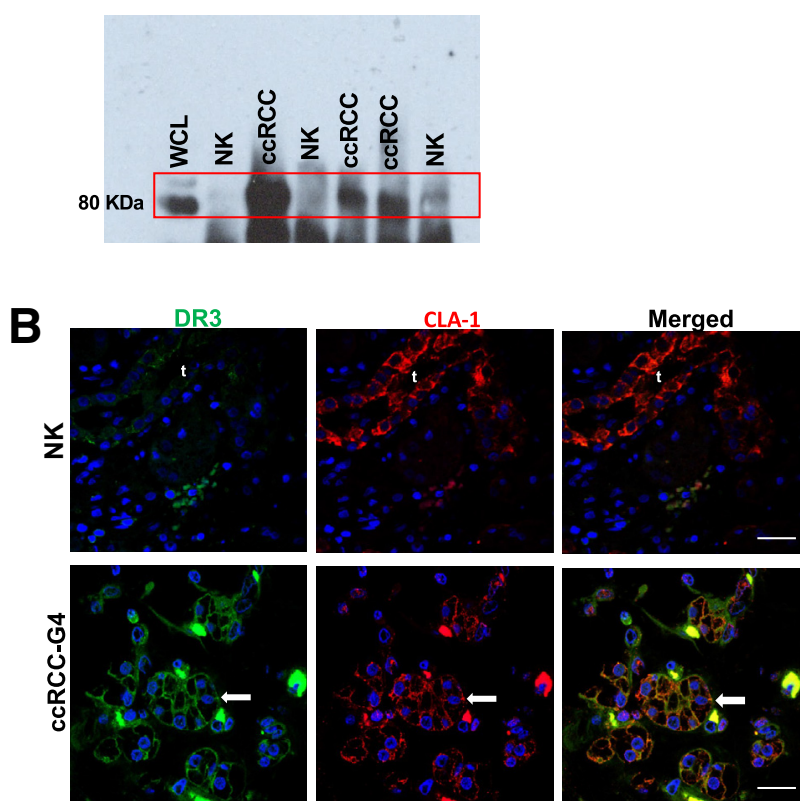

C
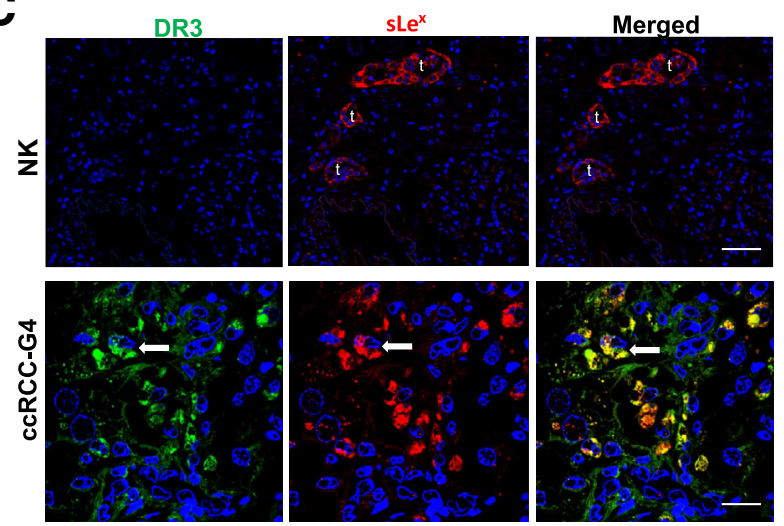

Figure 3 Immunoprecipitation of death receptor 3 (DR3) from extracts of clear cell renal cell carcinoma (ccRCC) and adjacent normal kidney (NK) followed by immunoblotting with antibody to cutaneous lymphocyte antigen (CLA)-1 (A) and representative confocal images of corresponding tissue dual immunostained for DR3 and CLA-1 (B) or sialyl Lewis $X\left(s^{X} e^{X}\right.$ (C). Strong $80-\mathrm{kDa}$ bands indicative of CLA-1, the appropriate size of DR3, is seen in all ccRCC extracts and to a lesser extent in the NK extracts (red box). Dual immunofluorescence shows co-signal for DR3 and CLA-1 or sLe in cCRCC grade 4 (G4) (arrows). In comparison, NK shows signal for CLA-1 or $s \mathrm{Le}^{\mathrm{X}}$ in normal tubular epithelial cells (t), negative for DR3. Nuclei were counterstained with Hoechst 333342 (blue). $n=10$ per group with similar results. Scale bars $=25 \mu \mathrm{M}$. Original magnification, $\times 63$. WCL, whole cell lysates (positive control).

established in our laboratory. ${ }^{7}$ Organ cultures were treated with TL1A, or left untreated. They were analyzed for the presence of phosphorylated p65 subunit of NF- $\kappa \mathrm{B}$ (NF$\kappa \mathrm{Bp} 65^{\mathrm{Ser} 276}$ ), indicative of induction of gene transcription, for the expression of various activated MAPKs, namely, p38, ERK, and JNK, using antibodies specific for the activated phosphorylated forms of these enzymes, and for the induction of cell-cycle entry comparing the expression of $\mathrm{pH} 3^{-\mathrm{Ser} 10}$, an indicator of cell proliferation. The effect of treatment on morphology was determined on H\&E-stained sections from all the cultures. Compared with UT controls, both the treatments induced distortion of the cell architecture, some areas of fibrosis, and thickened wall in some vessels (Supplemental Figure S4). IHC revealed a statistically significant increase in nuclear expression of NF- $\kappa \mathrm{Bp} 65^{\text {Ser276 }}$ in tumor cells in TL1A-treated cultures (approximately $42 \% \pm 0.2 \%$ ) and in vascular ECs in ccRCC compared with UT controls (approximately $4.5 \% \pm 0.6 \%$ ) (Figure $4 \mathrm{~A}$ ). TL1A also induced NF- $\mathrm{KBp} 65^{\text {Ser2276 }}$ expression in NK, which was less frequent by approximately 2.2-fold (approximately $19 \% \pm 0.8 \%$ ), with staining mainly confined to normal TECs and vascular ECs (Figure 4B). Tissue pretreated with Bay11-7082, an inhibitor of the enzyme IKK $\beta$, which is required for canonical NF- $\kappa B$ signaling, before the addition of TL1A showed weakened green fluorescence nuclei staining of p65 in both study groups with pronounced effects in ccRCC, consistent with canonical signaling (quantified in Figure 4C). Interestingly, TL1A also induced a statistically significant increase in the level of activation of MAPKs with a much pronounced signal for $\mathrm{p} 38$ and phosphorylated JNK than for phosphorylated ERK $P<0.001$ versus $P<0.05$ ) in ccRCC compared with NK (by approximately threefold) and UT controls and staining mainly localized to tumor cells, vascular ECs, and infiltrating cells (Figure 4D, quantified as CTCF in Figure 4E). Tumor cells (approximately $35.1 \% \pm 0.4 \%$ ) and vascular ECs in treated ccRCC also showed an increased expression of nuclear $\mathrm{pH}^{-\mathrm{Ser} 10}$ compared with UT controls (approximately $4.7 \% \pm 0.1 \%$ ), and treated cultures of NK showed a much reduced effect (by approximately twofold) with signal detected mainly in normal TECs (Figure 4F, quantified in Figure 4G). Cumulatively, these data demonstrate that DR3 in ccRCC tumor cells is functional, can activate NF- $\kappa \mathrm{B}$ and MAPKs, and promotes tumor cell cycle entry, indicative of mitogenesis.

\section{TL1A Signaling Induces the Expression of E-Selectin in ccRCC Cells}

The expression of E-selectin on ccRCC cells was unexpected and could arise from adsorption of shed E-selectin from ECs or de novo synthesis by ccRCC cells. To address this, the study analyzed the effect of TL1A on regulation of E-selectin mRNA and protein expression using organ cultures of low-grade ccRCC (grades 1 and 2). Signal for Eselectin protein and mRNA was seen in a few scattered tumor cells in UT controls, whereas TL1A-treated cultures showed an enhanced signal in tumor cells (approximately $26 \% \pm 0.6 \%$ ), vascular ECs, and infiltrating leukocytes (Figure 5A). In comparison, treatment induced a much reduced effect (approximately 7.0-fold less) in NK cultures with signal for both protein and mRNA seen in normal TECs and glomerular ECs. E-selectin protein was absent in UT controls of NK and signal for mRNA detected only in interlobular capillaries (Figure 5B). Fluorescence intensity in both study groups is presented as CTCF in Figure 5C. In 


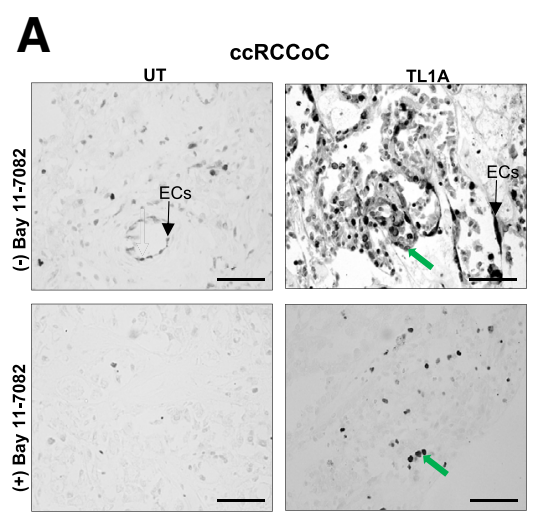

B
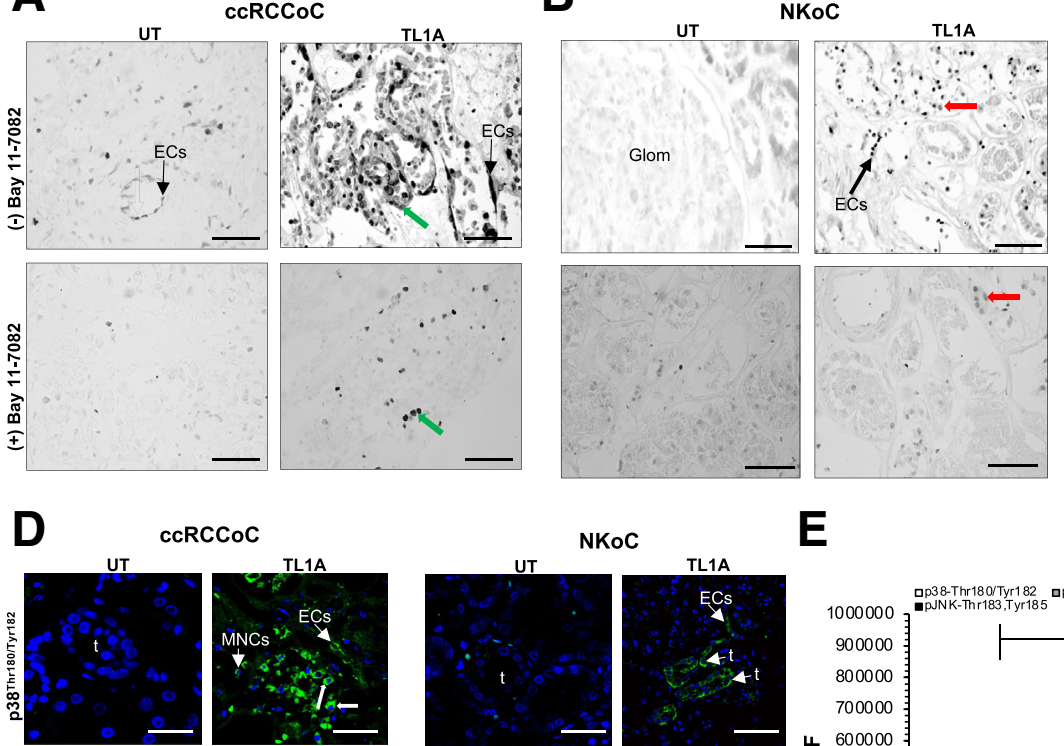

CRCCOC
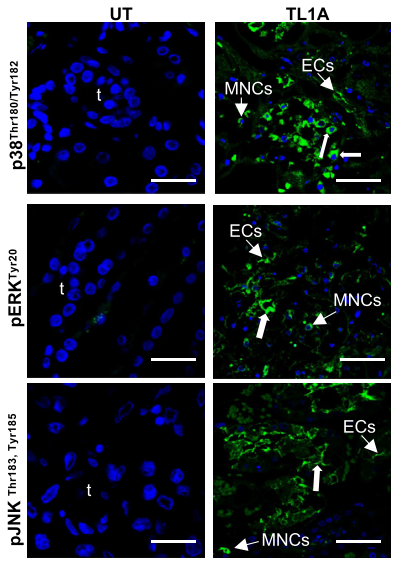
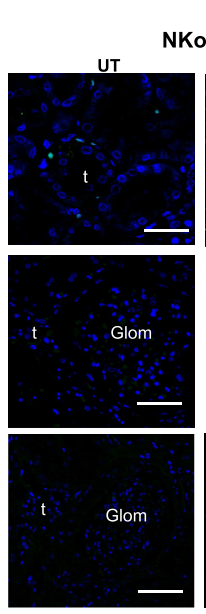

NKoC

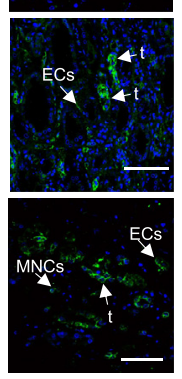

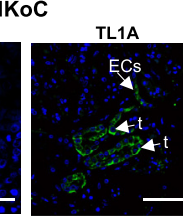

E

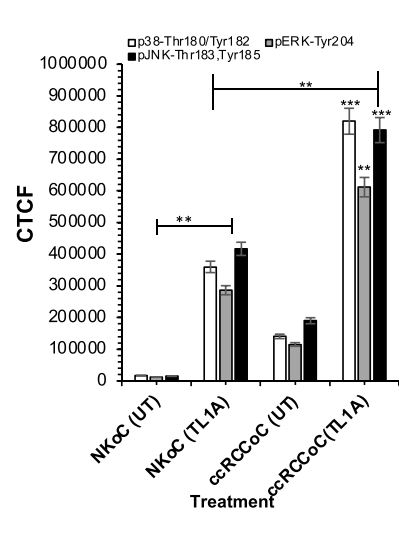

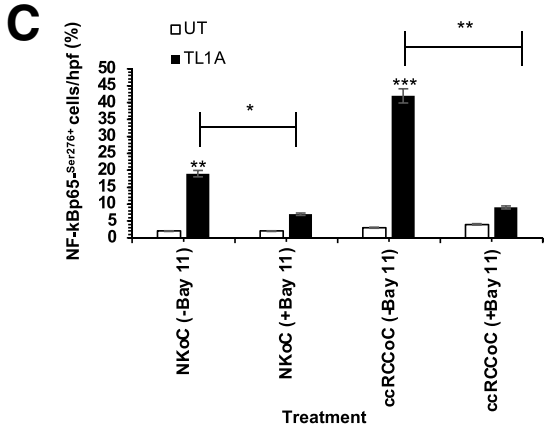

$\mathbf{F}$
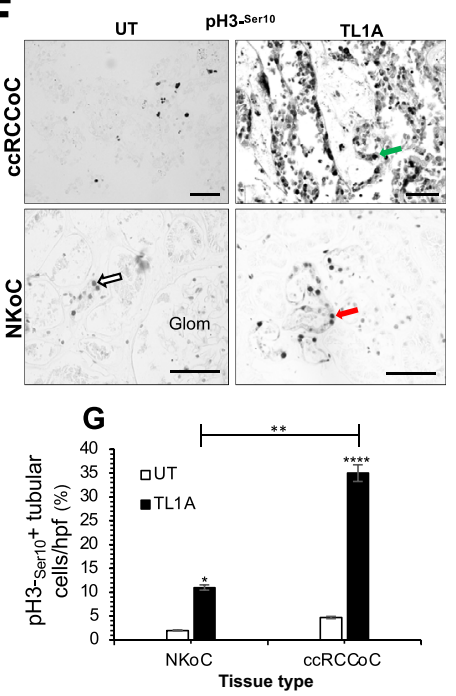

Figure 4 Response of $\mathrm{DR}^{+}{ }^{+} \mathrm{ccRCC}$ cells to tumor necrosis factor-like $1 \mathrm{~A}$ (TL1A). A: Light micrographs of the effect of TL1A on activation of NF- $\kappa \mathrm{B}$, mitogen-activated protein kinase (MAPK), and cell cycle entry in organ cultures of clear cell renal cell carcinoma (ccRCCoC) and adjacent normal kidney (NKoC). B: Untreated (UT) controls of ccRCC showing a rare nuclei signal for NF- $\kappa \mathrm{Bp} 65^{- \text {-Ser276 }}$ in vascular endothelial cells (ECS), which is remarkably increased in TL1Atreated cultures with signal mainly in tumor cells (green arrows) and in ECs, and significantly attenuated by pretreatment with Bay11-7082. C: Treated cultures of NK show a similar pattern of staining with signal mainly confined to normal tubular epithelial cells ( $t$ ) (red arrows) and in vascular ECs, attenuated by Bay11-7082. D: Quantification of the percentage of positive tumor cells and in CCRCC and NK. D: TL1A also induced expression for all the three kinases in both study groups with a strong signal localized in tumor cells (white arrows), ECs, infiltrating mononuclear cells (MNCs), t in NK compared with UT controls. E: Quantification of immunofluorescence presented as corrected total cell fluorescence (CTCF) in tumor cells and in normal $t$ in ccRCC and NK. F: Nuclear $\mathrm{pH}_{3}{ }^{\mathrm{Ser} 10}$ is rarely detected in UT controls, but expression is pronounced in tumor cells (green arrow) in TL1A-treated ccRCC cultures. Treated cultures of NK show a much-reduced level with signal seen in $\mathrm{t}$ (red arrow) and a rare signal detected in UT controls. G: Quantification of the percentage of positive $\mathrm{pH} 3 \mathrm{-}^{\mathrm{S}} \mathrm{er10}$ in tumor cells and t. Nuclei were counterstained with Hoechst 33342 (blue). Data are expressed as means \pm SEM. $n=5$ per group with similar results. ${ }^{*} P<0.05,{ }^{* *} P<0.01,{ }^{* * *} P<0.001$, and ${ }^{* * *} P<0.0001$. Scale bars: $100 \mu \mathrm{M}$ (A, B, and F); $25 \mu \mathrm{M}$ (D). Original magnification: $\times 400(\mathbf{A}, \mathbf{D}$, and $\mathbf{F}$; photomicrographs); $\times 40$ (A, D, and F; confocal images). Glom, glomeruli; hpf, high-power field.

addition, no signal was detected on sections hybridized with corresponding sense probes (data not shown). These data suggest that the TL1A can induce E-selectin mRNA and protein synthesis in both tumor cells and in tumor vascular ECs in ccRCC and that this response is much more pronounced in ccRCC compared with adjacent NK.

It was further assessed whether TL1A promotes interaction of DR3 and E-selectin or CLA-1 or sLe ${ }^{\mathrm{X}}$ using PLA on organ cultures of ccRCC and adjacent NK. Stimulation with TL1A enhanced the DR3-E-selectin, DR3-CLA-1, and DR3-sLe ${ }^{\mathrm{X}}$ interaction by approximately 4.6-fold (approximately 2.1-fold and 2.2-fold in organ cultures of ccRCC compared with NK), evidenced by numerous red fluorescent PLA spots within the cytoplasm of tumor cells (approximately 67 PLA spots per cell) compared with UT cultures (approximately 6 PLA spots per cell) for DR3-Eselectin (Figure 6A, C, and E, quantified in Figure 6B, D, and $F$ ). These data indicate the ability of TL1A to enhance interaction of DR3-E-selectin, DR3-CLA-1, and DR3$\mathrm{sLe}^{\mathrm{X}}$ in tumor cells in ccRCC. A summary of DR3 and Eselectin protein and mRNA expression and their localization in ccRCC and adjacent NK is presented in Table 1.

\section{$\mathrm{DR}^{+}{ }^{+} \mathrm{ccRCC}$ Cells Are Responsive to Soluble E-Selectin}

In a final series of experiments, the study explored whether the interactions demonstrated by PLA between DR3 and Eselectin expressed on ccRCC cells could involve signaling 


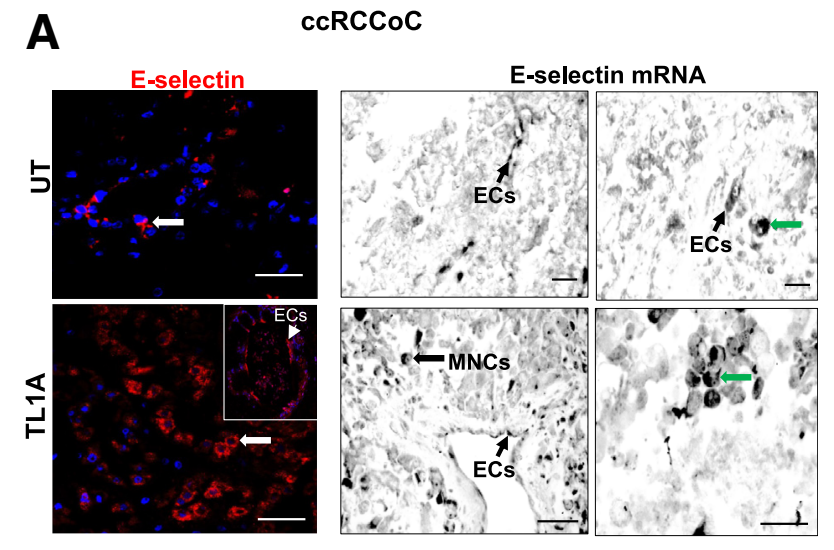

ccRCCoC

B
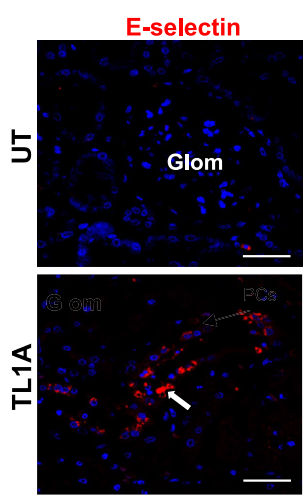

NKoC

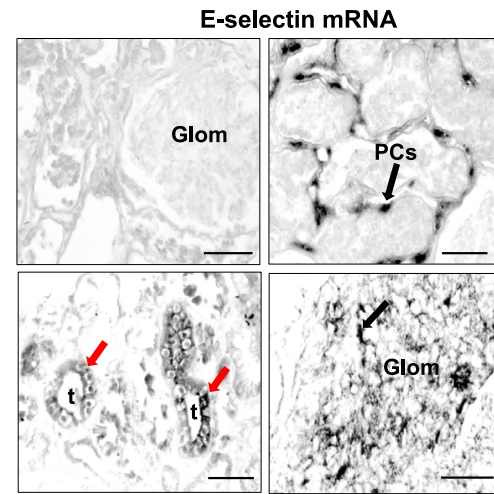

C

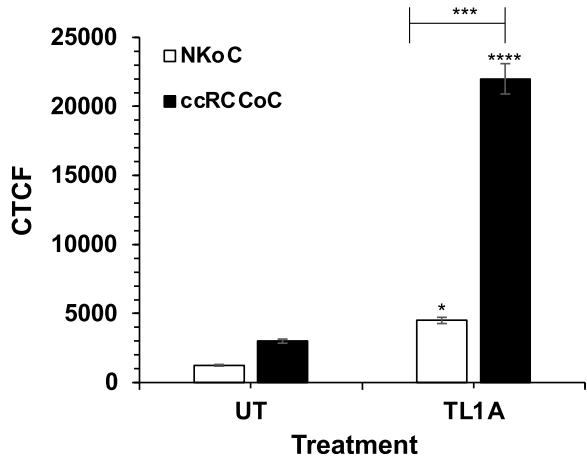

Figure 5 Representative confocal images and light micrographs of the effect of tumor necrosis factor-like $1 \mathrm{~A}$ (TL1A) on protein and mRNA expression for E-selectin in organ cultures of clear cell renal cell carcinoma (CCRCCoC) and adjacent normal kidney (NKoC). A: Untreated (UT) controls of cCRCC show Eselectin protein (white arrows) and mRNA in few isolated tumor cells (green arrows) and E-selectin mRNA in vascular endothelial cells (ECs), which was pronounced in TL1A-treated cultures. Treated cultures also show mRNA signal in scattered infiltrating mononuclear cells (MNCS). B: In contrast, UT controls of NK show absence of E-selectin protein but signal for mRNA in interlobular capillaries (PCs), whereas treated cultures show a strong signal for both protein (white arrow) and mRNA in normal tubular epithelial cells (t) (red arrows) and within glomeruli (Glom) ECs (black arrow). C: Quantification of immunofluorescence staining presented as corrected total cell fluorescence (CTCF). Nuclei were counterstained with Hoechst 33342 (blue). Data are expressed as means \pm SEM. $n=5$ per group with similar results. ${ }^{*} P<0.05,{ }^{* *} P<0.001$, and ${ }^{* * * * P}<0.0001$. Scale bars: $100 \mu \mathrm{M}$ (A and B, photomicrographs): $25 \mu \mathrm{M}$ (A and B, confocal images). Original magnification: $\times 400$ (A and B, photomicrographs); $\times 40$ (A and B, confocal images). through DR3. To explore this hypothesis, grade 1 ccRCC organ culture and adjacent $\mathrm{NK}$ were treated with exogenous sE-selectin and induction of DR3 and E-selectin protein and mRNA expression was analyzed by dual IF and in situ hydridization. A strong co-signal for DR3 and E-selectin protein was demonstrated in tumor cells (approximately $28 \% \pm 0.8 \%$ ) and in interlobular capillaries in treated cultures of ccRCC compared with UT controls (approximately $5.1 \% \pm 0.4 \%$ ), which showed co-signal in vascular ECs and in a few isolated tumor cells. Treatment also induced increased mRNA signal for both proteins in tumor cells, interlobular capillaries, and vascular ECs compared with UT controls, which showed a positive signal in vascular ECs and DR3 mRNA in isolated leukocytes (Figure 7A). A similar but much reduced effect of the treatment was evident in cultures of NK with co-signal for protein detected in normal TECs (approximately 12\% $\pm 0.7 \%$ ) and in vascular ECs but not in UT controls (Figure 7B). Treatment also induced mRNA signal for both epitopes in organ cultures of NK (mainly consisting of normal TECs, interlobular capillaries, vascular ECs, and glomerular ECs) at lower levels than in ccRCC cells and was absent in UT NK controls (Figure 7B). In addition, no signal was detected in parallel sections hybridized with sense probes (data now shown). Taken together, these data indicate TL1A-inducible upregulation of DR3/E-selectin expression in renal TECs at low levels and a marked increase in the magnitude of this response in ccRCC tumor cells.

Having established that DR3 signaling events activated by TL1A in tumor cells result in the induction of both DR3 and E-selectin expression and that induced E-selectin interacts with DR3, downstream cellular responses were analyzed to determine whether sE-selectin can function as a ligand for DR3 in ccRCC. For this, low-grade ccRCC and adjacent NK cultures were treated with sE-selectin and left UT and examined for the presence of NF- $\kappa B p 65^{\text {Ser276, }}$ activation of MAPKs, and induction of cell cycle entry. Nuclear NF- $\kappa$ Bp $65^{\text {Ser276 }}$ expression was induced in tumor cells (approximately $22.82 \% \pm 0.5 \%$ ) and in vascular ECs in treated cultures of ccRCC (Figure 8A, quantified in Figure 8B) compared with UT controls (approximately $4.63 \% \pm 0.3 \%$ ). In comparison, cultures of NK showed less marked effect (by approximately 2.7-fold) with signal detected mainly in normal TECs (approximately $8.42 \% \pm 0.1 \%$ ) and in vascular ECs compared with UT controls, which showed a rare signal (approximately $2.1 \% \pm 0.2 \%$ ). Pretreatment of parallel cultures with Bay11-7082 resulted in a significant reduction in NF$\kappa B p 65-{ }^{-S e r} 276$ signal (by approximately 4.3 -fold) in ccRCC compared with NK (by less than approximately twofold). Activation of MAPKs was noticeably increased in treated cultures of ccRCC with signal mainly confined to tumor cells and vascular ECs compared with UT controls, which showed no signal (Figure 8C). Fluorescence intensity calculated as CTCF is presented in Figure 8D. A much reduced intensity of staining (by approximately twofold) in 

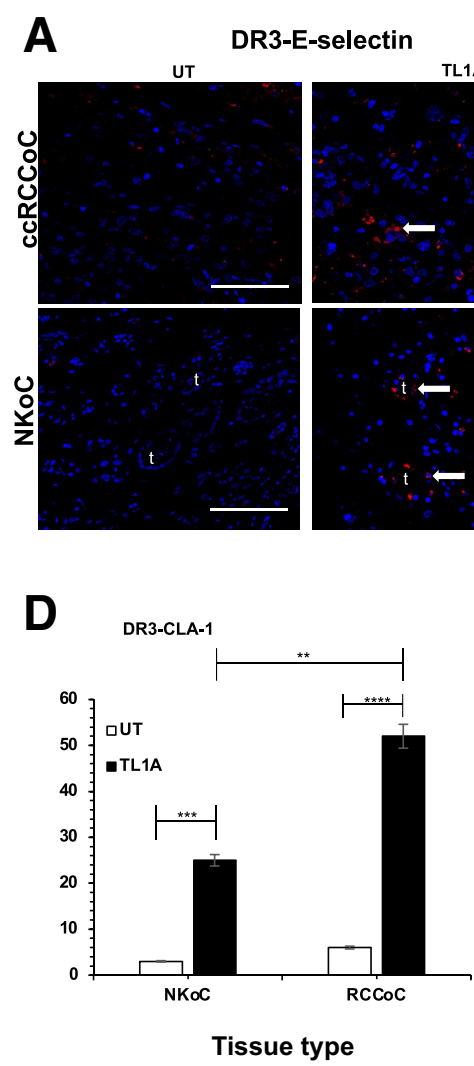

B
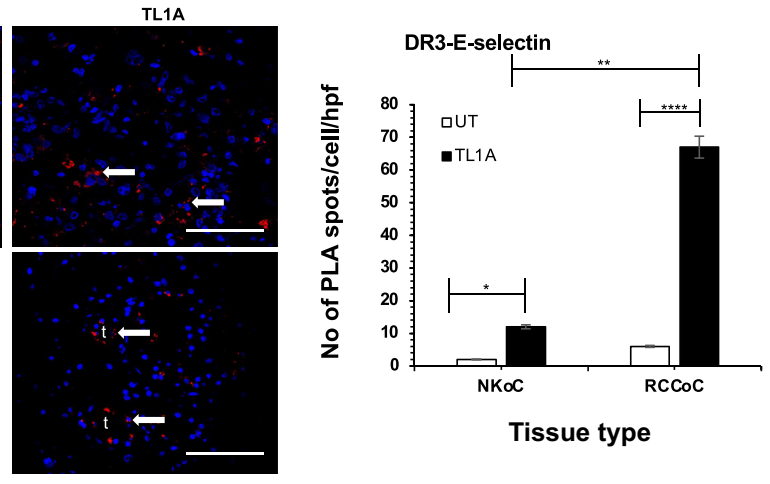

E

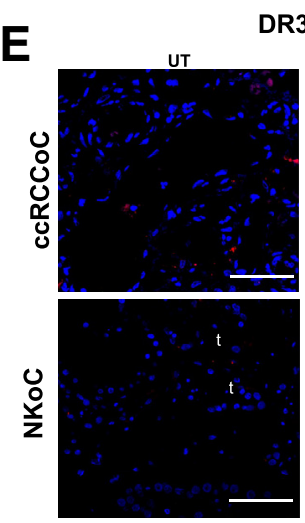

C

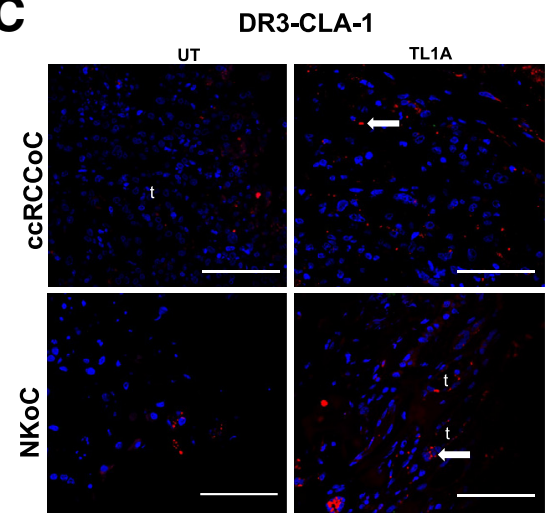

$\mathbf{F}$

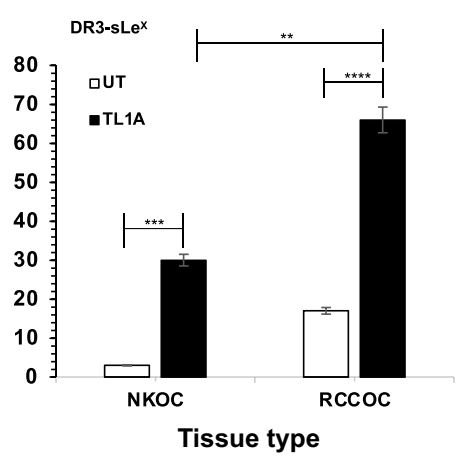

Figure 6 Proximity ligation assay (PLA) of organ cultures of clear cell renal cell carcinoma (ccRCCOC) grade 1 and adjacent normal kidney (NKoC) for detection of death receptor 3 (DR3) and E-selectin or cutaneous lymphocyte antigen (CLA)-1 or sialyl Lewis X (sLe ${ }^{X}$ ). A, C, and E: In comparison with untreated (UT) controls, tumor necrosis factor-like 1A (TL1A) treatment induced a strong interaction of DR3-E-selectin (A), DR3-CLA-1 (C), and DR3-sLe ${ }^{x}$ (E), appearing as strong red fluorescent spots mainly in cytoplasm of tumor cells and in normal tubular epithelial cells (t) (arrows). B, D, and F: Quantification of the number of PLA spots per cell in tumor cells and t show a statistically significant difference, more pronounced in ccRCCoC. Nuclei were counterstained with Hoechst 33342 (blue). $n=5$ per group with similar results. ${ }^{*} P<0.05,{ }^{*} P<0.01,{ }^{*} * P<0.001$, and ${ }^{* * * *} P<0.0001$. Scale bars $=75 \mu \mathrm{M}$. Original magnification, $\times 40$.

normal TECs was seen in NK. sE-selectin also induced a strong nuclear signal for $\mathrm{pH} 3-{ }^{\mathrm{Ser} 10}$ in tumor cells and in vascular ECs in ccRCC (approximately $23.5 \% \pm 0.3 \%$ versus approximately $5.2 \% \pm 0.1 \%$ in UT controls) compared with NK (approximately 10.2\% $\pm 0.2 \%$ versus $<2 \%$ in UT controls), with signal localized to normal TECs and vascular ECs (Figure 8E, quantified in Figure $8 \mathrm{~F}$ ).
These data are consistent with the interpretation that $\mathrm{sE}$ selectin activates NF- $\kappa \mathrm{B}, \mathrm{MAPKs}$, and cell cycle in tumor cells through DR3 in ccRCC and suggest that the same process could be occurring by interactions of endogenously induced DR3 and E-selectin. A summary of TL1A- and sEselectin-mediated responses in organ cultures of ccRCC and $\mathrm{NK}$ is presented Table 2.

Table 1 DR3 and E-Selectin Protein and mRNA Expression and Localization in Clinical Samples of cCRCC and NK

\begin{tabular}{|c|c|c|c|c|}
\hline \multirow[b]{2}{*}{ Variable } & \multicolumn{2}{|l|}{ NK } & \multicolumn{2}{|l|}{$\operatorname{ccRCC}$} \\
\hline & EPCs & VECs & EPCs & VECs \\
\hline DR3 & $\begin{array}{l}- \text { mRNA } \\
\pm \text { protein }\end{array}$ & $\begin{array}{l}- \text { mRNA } \\
\pm \text { protein }\end{array}$ & $\begin{array}{l}++++ \text { mRNA } \\
+++ \text { protein*; contains sLe }\end{array}$ & $\begin{array}{l}++++ \text { mRNA } \\
+++ \text { protein* }\end{array}$ \\
\hline E-selectin & - & - & $+++/+++^{*}$ & $\begin{array}{l}++++ \text { mRNA } \\
+++ \text { protein }\end{array}$ \\
\hline
\end{tabular}

Scores are as follows: - , no labeling; \pm , occasional positive labeling $(>2 \%) ;+++$, strong positive labeling $(>20 \%) ;++++$, very strong labeling $(>30 \%)$. *Increased with tumor grade.

ccRCC, clear cell renal cell carcinoma; DR3, death receptor 3; EPCs, epithelial cells; NK, normal kidney; sLe', sialyl Lewis X; VECs, vascular endothelial cells. 


\section{Discussion}

DR3 is induced in renal TECs and ECs in kidney injury associated with transplant rejection. ${ }^{6}$ Studies supporting this were extended to examine the expression of DR3 in a clinical cohort of excised ccRCC tumors because these cells are the malignant counterpart of tubular epithelium. DR3 was expressed in tumor cells and vascular ECs in ccRCC, and its expression increased with tumor grade. In endothelium, signaling through DR3 resulted in expression of E-selectin, thought to be a specific response of this cell type. Surprisingly DR3 ${ }^{+}$tumor cells also showed expression of E-selectin that increased with tumor grade. DR3 on ccRCC cells also contained $\mathrm{sLe}^{\mathrm{X}}$ and DR3 and E-selectin appeared to form complexes in ccRCC cells that could be detected by PLA. Stimulation of DR3 ${ }^{+}$ tumor cells in ccRCC organ culture with exogenous TL1A induced NF- $\kappa \mathrm{B}$ activation, increased phosphorylation of p38, ERK, and JNK at sites indicative of enzyme activation, and promoted cell cycle entry (indicated by $\mathrm{H} 3^{\text {Ser10 }}$ expression). Unexpectedly, TL1A also induced up-regulation of E-selectin protein/mRNA expression and promoted interaction of DR3 and Eselectin protein in tumor cells in ccRCC. Perhaps most surprisingly, exogenous sE-selectin also induced $\mathrm{NF}-\kappa \mathrm{B}$ activation, increased phosphorylation of p38, ERK, and JNK MAPKs, and promoted cell cycle entry in DR3 ${ }^{+}$ tumor cells. Exogenous sE-selectin-induced responses appeared less pronounced than those induced by TL1A. This difference may be ascribed to an artifact of differences in the concentrations of ligands use or in affinity of sE-selectin and TL1A for DR3 or that many $\mathrm{sLe}^{\mathrm{X}}$ groups on DR3 are already engaged by endogenous E-selectin and unavailable for binding and hence DR3 clustering. TL1A and sE-selectin induced similar effects in organ cultures of NK but to a much lower extent.

A

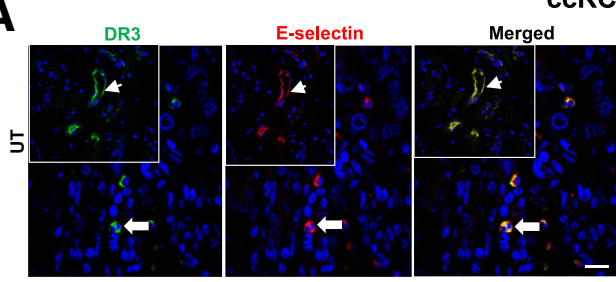

ccRCCoC
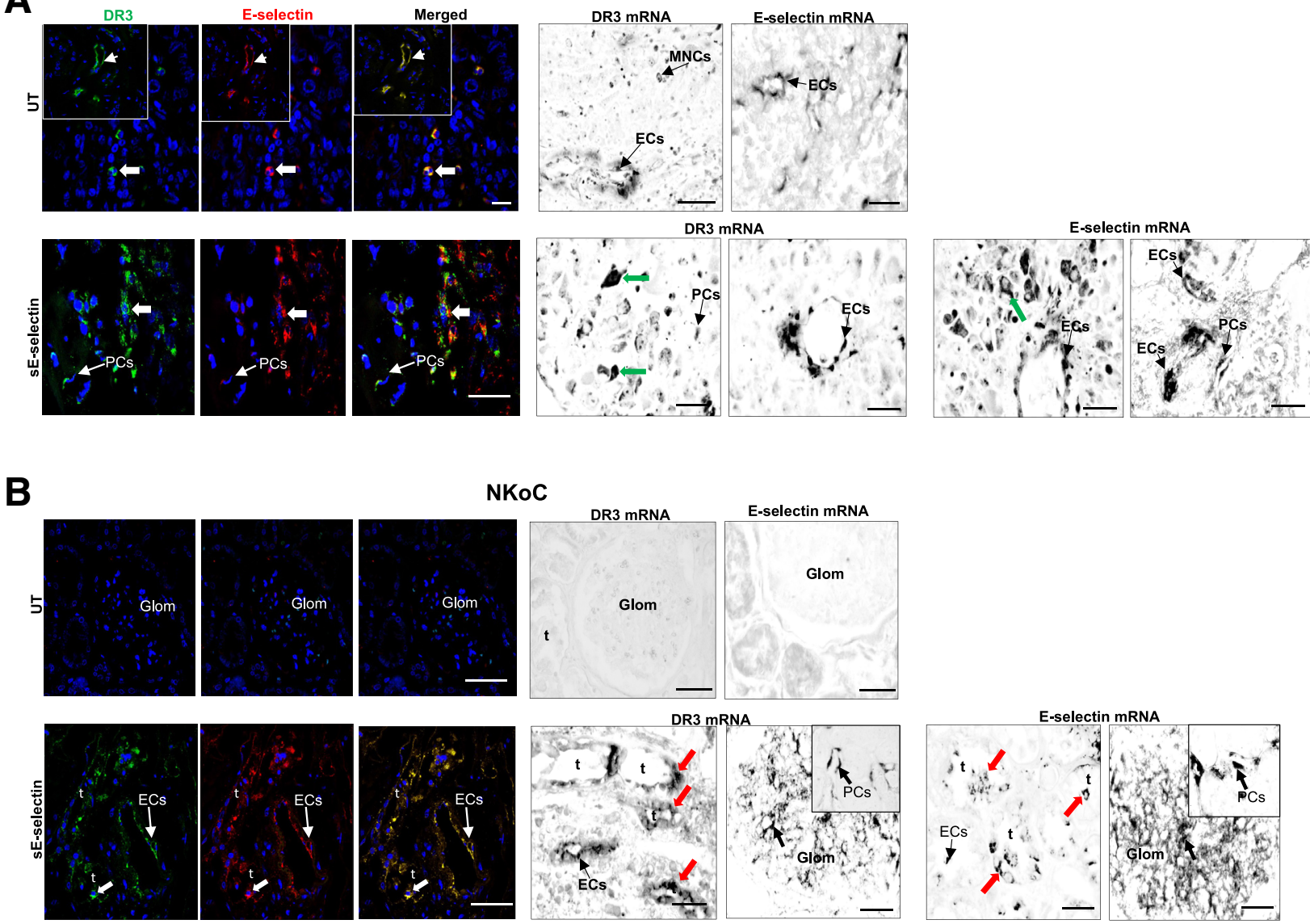

Figure 7 Representative confocal images and light micrographs of the effect of soluble E-selection (sE-selectin) on protein and mRNA expression for death receptor 3 (DR3) and E-selectin in organ cultures of clear cell renal cell carcinoma (ccRCCoC) and adjacent normal kidney (NKoC). A: Untreated (UT) controls of ccRCC show co-signal for DR3 and E-selectin protein in a few isolated tumor cells (white arrows) and in vascular endothelial cells (ECs). mRNA signal for both DR3 and E-selectin is seen ECs and DR3 mRNA in scattered infiltrating mononuclear cells (MNCs). A similar pattern with a much more pronounced signal is detected in tumor cells (green arrows) and in interlobular capillaries (PCs) in treated cultures. B: In contrast, UT controls of NK show an absence of signal, but a strong signal is detected in treated cultures mainly confined in normal tubular epithelial cells (t) (red arrows), vascular ECs, and glomeruli (Glom). $n=5$ per group with similar results. Scale bars: $100 \mu \mathrm{M}$ (photomicrographs); $25 \mu \mathrm{M}$ (confocal images). Original magnification: $\times 400$ (photomicrographs); $\times 40$ (confocal images). 

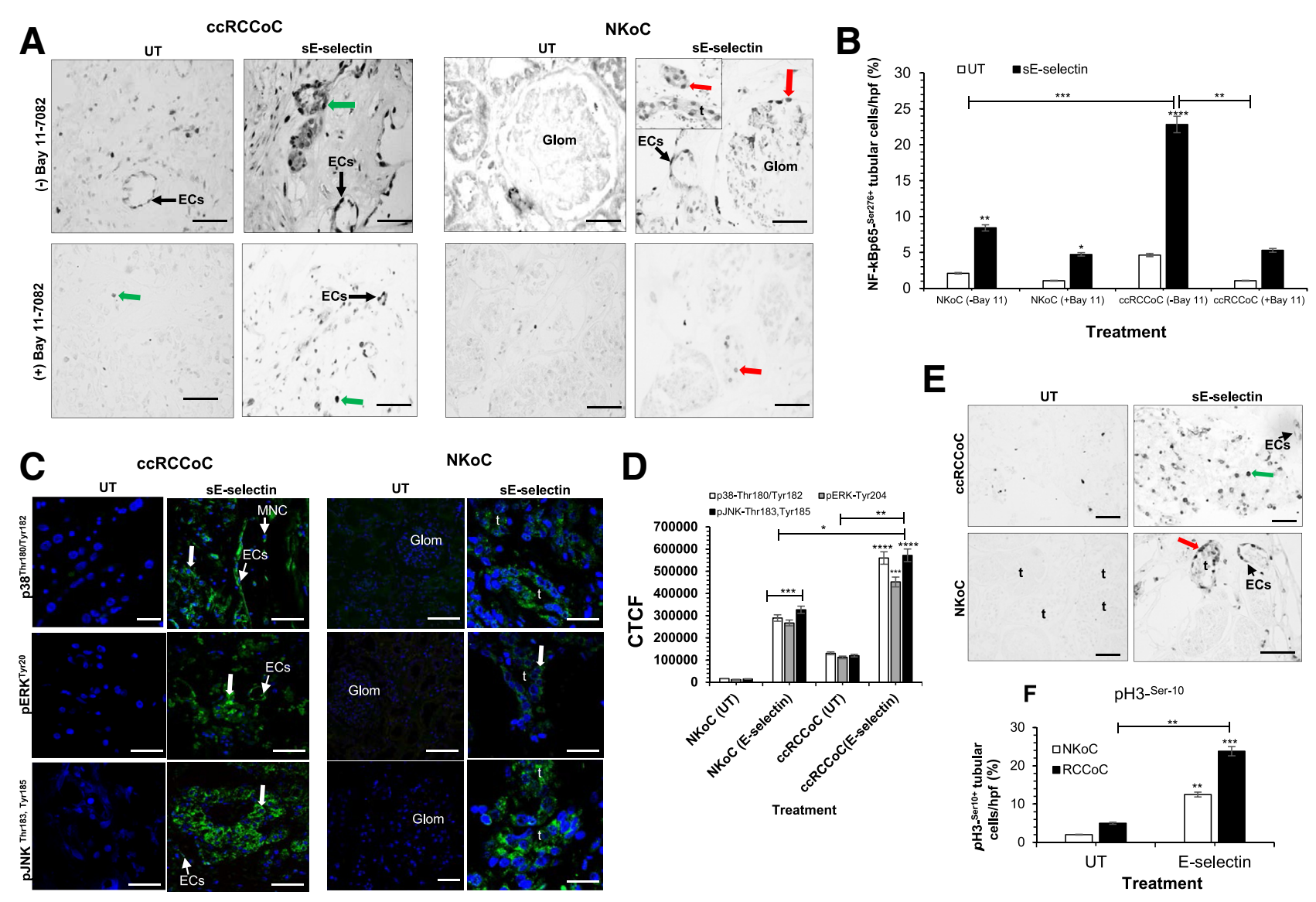

Figure 8 Light micrographs of the effect of soluble E-selection (sE-selectin) on activation of NF- $\kappa$ B, mitogen-activated kinases (MAPKs), and cell cycle entry on organ cultures of clear cell renal cell carcinoma ( $c c R C C O C)$ and adjacent normal kidney (NKoC). A: Untreated (UT) cultures of ccRCC show a rare nuclei signal for NF-KBp65 $5^{-S e r 276}$ in vascular endothelial cells (ECs), noticeably increased in treated cultures with signal mainly confined to tumor cells (green arrows) and in ECs, and significantly attenuated in cultures pretreated with Bay11-7082. Similarly, UT cultures of NK show a negligible signal, which is increased in treated cultures mainly confined to tubular epithelial cells ( $t$ ) (red arrows), in vascular ECs, and within glomerular (Glom), with a diminished signal in cultures pretreated with Bay11-7082. B: Quantification of the percentage of positive tumor cells and t. C: Both treated study groups show induction of expression for all the three kinases, with signal mainly confined to tumor cells (white arrows) and in vascular ECs and infiltrating mononuclear cells (MNCs) in cultures of cCRCC and in $t$ in cultures of NK. D: Quantification of immunofluorescence presented as calculated total cell fluorescence (CTCF) in tumor cells and $t$ in cultures of ccRCC and NK. E: UT organ cultures of ccRCC show a negligible level of signal for $\mathrm{pH}^{-\mathrm{Ser} 10}$ in nuclei of tumor cells, significantly increases in cultures treated with sE-selectin (green arrow), and detected in vascular ECs. Similar induction of signal is detected in cultures of NK but less pronounced with signal mainly confined to normal $t$ (red arrow). F: Quantification of the percentages of positive tumor cells and normal t. Data are presented as means \pm SEM. $n=5$ per group with similar results. ${ }^{*} P<0.05,{ }^{* *} P<0.01,{ }^{*} * P<0.001$, and ${ }^{* * *} P<0.0001$. Scale bars $=100 \mu \mathrm{M}$ (A and E); $50 \mu \mathrm{M}$ (C). Original magnification: $\times 400$ (photomicrographs); $\times 40$ (confocal images).

Currently, little is known about the role(s) of DR3 in cancer, particularly its potential as an antitumor target. Increased levels of DR3 expression have been reported in various cancer cell lines and tumors compared with normal counterparts. ${ }^{13,48-50}$ DR3 mRNA encoding the membrane and soluble receptors has been reported in colorectal cancer, ${ }^{50}$ and DR3 transcript expression levels are increased in

high-grade breast tumors. ${ }^{48}$ As noted above, a potential cancer migratory role for DR3 has also been previously highlighted, ${ }^{48}$ and DR3 has been reported to be a new receptor for E-selectin that confers metastatic and survival advantages to colon cancer via MAPKs ${ }^{13}$ and phosphatidylinositol 3-kinase/NF- $\kappa \mathrm{B}$ axis. ${ }^{51}$ The current observation that DR3 in tumor cells was induced by TL1A and sE-

Table 2 TL1A and E-Selectin-Mediated Responses in Organ Cultures of cCRCC and NK

\begin{tabular}{|c|c|c|c|c|c|c|}
\hline \multirow[b]{2}{*}{ Ligand } & \multicolumn{3}{|l|}{ NK } & \multicolumn{3}{|l|}{ ccRCC } \\
\hline & NF-кBp65 $5^{\text {Ser276 }}$ & $\mathrm{pH} 3-\operatorname{Ser} 10$ & MAPKs & NF-кBp65 & $\mathrm{pH} 3-\operatorname{Ser} 10$ & MAPKs \\
\hline TL1A & +++ & ++ & +++ & ++++ & ++++ & $\overline{++++}$ \\
\hline
\end{tabular}

Scores as as follows: ++ , intermediate labeling $(>10 \%) ;+++$, strong labeling, ++++ , very strong labeling $(>30 \%)$.

cCRCC, clear cell renal cell carcinoma; MAPKs, mitogen-activated protein kinases; NF- $\kappa B p 65^{\text {Ser276, }}$, NF- $\kappa$ B phosphorylated at 65 subunits at serine 276 ; NK, normal kidney; $\mathrm{pH}_{3}{ }^{-\mathrm{Ser} 10}$, phosphorylated histone $\mathrm{H} 3$ at Serine10; TL1A, tumor necrosis factor-like ligand A1. 
selectin suggests that it is a functional receptor in ccRCC with the ability to activate downstream pathways that promote survival/growth signals. Interestingly, DR3 is labeled as a death receptor, but its activation by sE-selectin does not induce apoptosis in colon cancer cells, except when ERK is inhibited. ${ }^{13}$ A previous study by Wen et $\mathrm{al}^{52}$ reported that the binding of TL1A to DR3 activated the ERK pathway, whereas JNK and apoptosis-inhibiting protein c-IAP2 prevented DR3-mediated apoptosis in TF-1 cells. Because DR3 uses the same signaling apparatus as TNFR1 for both protein induction and apoptosis initiation, it is also possible that TNF-inducible antiapoptotic proteins, such as cellular FADD-like IL-1 $\beta$ converting enzyme-inhibitory protein, are induced and then play a protective role.

Accumulating evidence suggests that E-selectin facilitates metastasis in various cancers. ${ }^{28,29,49,53-55}$ The mechanism entails adhesion cascade governed by cell-cell interactions between circulating tumor cells and vascular ECs through a sequential affinity interaction between adhesion molecules and the counterreceptor ligand. ${ }^{13}$ Herein, E-selectin expression was documented in tumor cells in ccRCC, which was unexpected. However, epithelial cell expression of Eselectin has been previously reported in human colonic epithelium. ${ }^{24}$ The factors that result in preferential expression of E-selectin in ccRCC cells and its pathogenic importance are at present unclear. Although the major role of E-selectin expression on ccRCC tumor cells is likely to be autocrine/paracrine signaling, it also could function to retain leukocytes within the tumor microenvironment.

The current findings on E-selectin/DR3 interaction in cancer cells and their growth-promoting properties suggest that disruption of this signaling axis could be a new approach to treating high-grade ccRCC. Specifically, smallmolecule inhibitors that mimic CLA epitopes could prevent E-selectin from engaging DR3, although it will be important to assess whether these moieties induce signaling. Such potential inhibitors may already have been developed and tested for inhibiting E-selectin-mediated recruitment of leukocytes.

\section{Acknowledgment}

We thank the Human Research Tissue Bank supported by the National Institute of Health Research Cambridge Biomedical Research Centre at the Cambridge University Hospitals National Health Service Foundation Trust for help in accessing tissue.

\section{Author Contributions}

R.S.A.-L., J.S.P., J.R.B. designed the experiments; R.S.A.-L. and J.W. performed the experiments and analyzed the data; J.R.B. secured funding. R.S.A.-L. is the guarantor of this work and, as such, had full access to all of the data in the study and takes responsibility for the integrity of the data and the accuracy of the data analysis.

\section{Supplemental Data}

Supplemental material for this article can be found at http://doi.org/10.1016/j.ajpath.2021.12.010.

\section{References}

1. Leibovich BC, Lohse CM, Crispen PL, Boorjian SA, Thompson RH, Blute ML, Cheville JC: Histological subtype is an independent predictor of outcome for patients with renal cell carcinoma. J Urol 2010, 183:1309-1315

2. Ashkenazi A, Dixit VM: Death receptors: signaling and modulation. Science 1998, 281:1305-1308

3. Kitson J, Raven T, Jiang YP, Goeddel DV, Giles KM, Pun KT, Grinham CJ, Brown R, Farrow SN: A death-domain-containing receptor that mediates apoptosis. Nature 1996, 384:372-375

4. Muppidi JR, Tschopp J, Siegel RM: Life and death decisions: secondary complexes and lipid rafts in TNF receptor family signal transduction. Immunity 2004, 21:461-465

5. Pobezinskaya YL, Choksi S, Morgan MJ, Cao X, Liu ZG: The adaptor protein TRADD is essential for TNF-like ligand 1A/death receptor 3 signaling. J Immunol 2011, 186:5212-5216

6. Al-Lamki RS, Wang J, Thiru S, Pritchard NR, Bradley JA, Pober JS, Bradley JR: Expression of silencer of death domains and deathreceptor-3 in normal human kidney and in rejecting renal transplants. Am J Pathol 2003, 163:401-411

7. Al-Lamki RS, Wang J, Tolkovsky AM, Bradley JA, Griffin JL, Thiru S, Wang EC, Bolton E, Min W, Moore P, Pober JS, Bradley JR: TL1A both promotes and protects from renal inflammation and injury. J Am Soc Nephrol 2008, 19:953-960

8. Al-Lamki RS, Lu W, Finlay S, Twohig JP, Wang EC, Tolkovsky AM, Bradley JR: DR3 signaling protects against cisplatin nephrotoxicity mediated by tumor necrosis factor. Am J Pathol 2012, 180:1454-1464

9. Twohig JP, Roberts MI, Gavalda N, Rees-Taylor EL, Giralt A, Adams D, Brooks SP, Bull MJ, Calder CJ, Cuff S, Yong AA, Alberch J, Davies A, Dunnett SB, Tolkovsky AM, Wang EC: Agedependent maintenance of motor control and corticostriatal innervation by death receptor 3. J Neurosci 2010, 30:3782-3792

10. Slebioda TJ, Stanislawowski M, Cyman M, Wierzbicki PM, ZurawaJanicka D, Kobiela J, Makarewicz W, Guzek M, Kmiec Z: Distinct expression patterns of two tumor necrosis factor superfamily member 15 gene isoforms in human colon cancer. Dig Dis Sci 2019, 64: $1857-1867$

11. Choi KE, Hwang CJ, Gu SM, Park MH, Kim JH, Park JH, Ahn YJ, Kim JY, Song MJ, Song HS, Han SB, Hong JT: Cancer cell growth inhibitory effect of bee venom via increase of death receptor 3 expression and inactivation of NF-kappa B in NSCLC cells. Toxins (Basel) 2014, 6:2210-2228

12. Ge Z, Sanders AJ, Ye L, Jiang WG: Aberrant expression and function of death receptor-3 and death decoy receptor-3 in human cancer. Exp Ther Med 2011, 2:167-172

13. Gout S, Morin C, Houle F, Huot J: Death receptor-3, a new E-selectin counter-receptor that confers migration and survival advantages to colon carcinoma cells by triggering p38 and ERK MAPK activation. Cancer Res 2006, 66:9117-9124

14. Bevilacqua MP, Stengelin S, Gimbrone MA Jr, Seed B: Endothelial leukocyte adhesion molecule 1: an inducible receptor for neutrophils related to complement regulatory proteins and lectins. Science 1989 , 243:1160-1165 
15. Cotran RS, Gimbrone MA Jr, Bevilacqua MP, Mendrick DL, Pober JS: Induction and detection of a human endothelial activation antigen in vivo. J Exp Med 1986, 164:661-666

16. Gillies PJ, Richardson NA, Walshe J, Stephenson SA, Dawson RA, Harkin DG: Demonstration of P-selectin expression and potential function in human corneal epithelial cells. Exp Eye Res 2018, 176:196-206

17. Pietrzak ER, Savage NW, Aldred MJ, Walsh LJ: Expression of the Eselectin gene in human gingival epithelial tissue. J Oral Pathol Med 1996, 25:320-324

18. Collins T, Read MA, Neish AS, Whitley MZ, Thanos D, Maniatis T: Transcriptional regulation of endothelial cell adhesion molecules: NFkappaB and cytokine-inducible enhancers. FASEB J 1995, 9: 899-909

19. Higai K, Ishihara S, Matsumoto K: NFkappaB-p65 dependent transcriptional regulation of glycosyltransferases in human colon adenocarcinoma HT-29 by stimulation with tumor necrosis factor alpha. Biol Pharm Bull 2006, 29:2372-2377

20. Vora M, Romero LI, Karasek MA: Interleukin-10 induces E-selectin on small and large blood vessel endothelial cells. J Exp Med 1996, $184: 821-829$

21. Pober JS: Activation and injury of endothelial cells by cytokines. Pathol Biol (Paris) 1998, 46:159-163

22. Bhaskar V, Law DA, Ibsen E, Breinberg D, Cass KM, DuBridge RB, Evangelista F, Henshall SM, Hevezi P, Miller JC, Pong M, Powers R, Senter P, Stockett D, Sutherland RL, von Freeden-Jeffry U, Willhite D, Murray R, Afar DE, Ramakrishnan V: E-selectin up-regulation allows for targeted drug delivery in prostate cancer. Cancer Res 2003, 63:6387-6394

23. Hartwell DW, Wagner DD: New discoveries with mice mutant in endothelial and platelet selectins. Thromb Haemost 1999, 82: $850-857$

24. Vainer B, Nielsen OH, Horn T: Expression of E-selectin, sialyl Lewis $\mathrm{X}$, and macrophage inflammatory protein-1alpha by colonic epithelial cells in ulcerative colitis. Dig Dis Sci 1998, 43:596-608

25. Brodt P, Fallavollita L, Bresalier RS, Meterissian S, Norton CR, Wolitzky BA: Liver endothelial E-selectin mediates carcinoma cell adhesion and promotes liver metastasis. Int J Cancer 1997, 71: 612-619

26. Dimitroff CJ, Lechpammer M, Long-Woodward D, Kutok JL: Rolling of human bone-metastatic prostate tumor cells on human bone marrow endothelium under shear flow is mediated by E-selectin. Cancer Res 2004, 64:5261-5269

27. Kang SA, Blache CA, Bajana S, Hasan N, Kamal M, Morita Y, Gupta V, Tsolmon B, Suh KS, Gorenstein DG, Razaq W, Rui H, Tanaka T: The effect of soluble E-selectin on tumor progression and metastasis. BMC Cancer 2016, 16:331

28. Khatib AM, Fallavollita L, Wancewicz EV, Monia BP, Brodt P: Inhibition of hepatic endothelial E-selectin expression by C-raf antisense oligonucleotides blocks colorectal carcinoma liver metastasis. Cancer Res 2002, 62:5393-5398

29. Sawada R, Tsuboi S, Fukuda M: Differential E-selectin-dependent adhesion efficiency in sublines of a human colon cancer exhibiting distinct metastatic potentials. J Biol Chem 1994, 269: $1425-1431$

30. Brandley BK, Kiso M, Abbas S, Nikrad P, Srivasatava O, Foxall C, Oda Y, Hasegawa A: Structure-function studies on selectin carbohydrate ligands. Modifications to fucose, sialic acid and sulphate as a sialic acid replacement. Glycobiology 1993, 3:633-641

31. Koenig A, Jain R, Vig R, Norgard-Sumnicht KE, Matta KL, Varki A: Selectin inhibition: synthesis and evaluation of novel sialylated, sulfated and fucosylated oligosaccharides, including the major capping group of GlyCAM-1. Glycobiology 1997, 7: 79-93

32. Nelson RM, Dolich S, Aruffo A, Cecconi O, Bevilacqua MP: Higheraffinity oligosaccharide ligands for E-selectin. J Clin Invest 1993, 91 : $1157-1166$
33. Renkonen J, Paavonen T, Renkonen R: Endothelial and epithelial expression of sialyl Lewis(x) and sialyl Lewis(a) in lesions of breast carcinoma. Int J Cancer 1997, 74:296-300

34. Skorstengaard K, Vestergaard EM, Langkilde NC, Christensen LL, Wolf H, Orntoft TF: Lewis antigen mediated adhesion of freshly removed human bladder tumors to E-selectin. J Urol 1999, 161: $1316-1323$

35. Cordon-Cardo C, Reuter VE, Finstad CL, Sheinfeld J, Lloyd KO, Fair WR, Melamed MR: Blood group-related antigens in human kidney: modulation of Lewis determinants in renal cell carcinoma. Cancer Res 1989, 49:212-218

36. Zetter BR: Adhesion molecules in tumor metastasis. Semin Cancer Biol 1993, 4:219-229

37. Kovacs G, Akhtar M, Beckwith BJ, Bugert P, Cooper CS, Delahunt B, Eble JN, Fleming S, Ljungberg B, Medeiros LJ, Moch H, Reuter VE, Ritz E, Roos G, Schmidt D, Srigley JR, Storkel S, van den Berg E, Zbar B: The Heidelberg classification of renal cell tumours. J Pathol 1997, 183:131-133

38. Fuhrman SA, Lasky LC, Limas C: Prognostic significance of morphologic parameters in renal cell carcinoma. Am J Surg Pathol 1982, 6:655-663

39. Al-Lamki RS, Sadler TJ, Wang J, Reid MJ, Warren AY, Movassagh M, Lu W, Mills IG, Neal DE, Burge J, Vandenebeele P. Pober JS, Bradley JR: Tumor necrosis factor receptor expression and signaling in renal cell carcinoma. Am J Pathol 2010, 177: 943-954

40. Guinan P, Sobin LH, Algaba F, Badellino F, Kameyama S, MacLennan G, Novick A: TNM staging of renal cell carcinoma: workgroup No. 3. Union International Contre le Cancer (UICC) and the American Joint Committee on Cancer (AJCC). Cancer 1997, 80: 992-993

41. Al-Lamki RS, Wang J, Vandenabeele P, Bradley JA, Thiru S, Luo D, Min W, Pober JS, Bradley JR: TNFR1- and TNFR2-mediated signaling pathways in human kidney are cell type-specific and differentially contribute to renal injury. FASEB J 2005, 19: $1637-1645$

42. Cheng Y, Liu B, Qian H, Yang H, Wang Y, Wu Y, Shen F: BAY117082 inhibits the expression of tissue factor and plasminogen activator inhibitor-1 in type-II alveolar epithelial cells following TNF-alpha stimulation via the NF-kappaB pathway. Exp Ther Med 2021, 21:177

43. Shindler KS, Roth KA: Double immunofluorescent staining using two unconjugated primary antisera raised in the same species. J Histochem Cytochem 1996, 44:1331-1335

44. Al-Lamki RS, Lu W, Manalo P, Wang J, Warren AY, Tolkovsky AM, Pober JS, Bradley JR: Tubular epithelial cells in renal clear cell carcinoma express high RIPK1/3 and show increased susceptibility to TNF receptor 1-induced necroptosis. Cell Death Dis 2016, 7:e2287

45. Al-Lamki RS, Wang J, Skepper JN, Thiru S, Pober JS, Bradley JR: Expression of tumor necrosis factor receptors in normal kidney and rejecting renal transplants. Lab Invest 2001, 81:1503-1515

46. Rossiter H, van Reijsen F, Mudde GC, Kalthoff F, BruijnzeelKoomen CA, Picker LJ, Kupper TS: Skin disease-related T cells bind to endothelial selectins: expression of cutaneous lymphocyte antigen (CLA) predicts E-selectin but not P-selectin binding. Eur J Immunol 1994, 24:205-210

47. An J, Liu H, Magyar CE, Guo Y, Veena MS, Srivatsan ES, Huang J, Rettig MB: Hyperactivated JNK is a therapeutic target in pVHL-deficient renal cell carcinoma. Cancer Res 2013, 73: $1374-1385$

48. Ge Z, Sanders AJ, Ye L, Mansel RE, Jiang WG: Expression of death receptor-3 in human breast cancer and its functional effects on breast cancer cells in vitro. Oncol Rep 2013, 29:1356-1364

49. Laferriere J, Houle F, Huot J: Regulation of the metastatic process by E-selectin and stress-activated protein kinase-2/p38. Ann N Y Acad Sci 2002, 973:562-572 
50. Utkin OV, Starikova VD, Perenkov AD, Ianchenko OS, Baryshnikov A, Novikov VV: [DR3/LARD mRNA spliced variants' frequency at colorectal cancer]. Mol Biol (Mosk) 2013, 47:828-834

51. Porquet N, Poirier A, Houle F, Pin AL, Gout S, Tremblay PL, Paquet ER, Klinck R, Auger FA, Huot J: Survival advantages conferred to colon cancer cells by E-selectin-induced activation of the PI3K-NFkappaB survival axis downstream of death receptor-3. BMC Cancer 2011, 11:285

52. Wen L, Zhuang L, Luo X, Wei P: TL1A-induced NF-kappaB activation and c-IAP2 production prevent DR3-mediated apoptosis in TF-1 cells. J Biol Chem 2003, 278:39251-39258
53. Dimitroff CJ, Descheny L, Trujillo N, Kim R, Nguyen V, Huang W, Pienta KJ, Kutok JL, Rubin MA: Identification of leukocyte E-selectin ligands, P-selectin glycoprotein ligand-1 and E-selectin ligand-1, on human metastatic prostate tumor cells. Cancer Res 2005, 65: $5750-5760$

54. Kobayashi K, Matsumoto S, Morishima T, Kawabe T, Okamoto T: Cimetidine inhibits cancer cell adhesion to endothelial cells and prevents metastasis by blocking E-selectin expression. Cancer Res 2000, 60:3978-3984

55. Shirure VS, Henson KA, Schnaar RL, Nimrichter L, Burdick MM: Gangliosides expressed on breast cancer cells are E-selectin ligands. Biochem Biophys Res Commun 2011, 406:423-429 